Market Development in the Experience in the Unired United Kingdom's Natural Gas Industry

Kingdom shows that it is possible to move from a monopoly to a competitive environment in natural gas without structural reforms,

Andrej Juris

although it is costly and

difficult. Deregulation must be accompanied by the creation of an appropriate regulatory and institutional framework for the sector that shields entrants from the exercise of market power by the incumbent and gives entrants in the gas market equal rights in dealing with the transportation monopolist.

The World Bank

Private Sector Development Department Private Participation in Infrastructure Division March 1998 


\section{Summary findings}

Juris shows how, in the United Kingdom, government and industry participants have responded to challenges created by opening the natural gas industry to competition. He concludes that, as a result of cooperation between the government and industry participants, appropriate mechanisms can be established for operating and balancing the system and for trading natural gas and transportation capacity. The deintegrated natural gas industry in the United Kingdom is off to a promising start after a long gestation.

Juris describes the processes of the Network Code, a market-based method for balancing the pipeline system and optimizing transportation by British Gas TransGo (BGT), the transportation and storage arm of British Gas (formerly the publicly owned monopoly transporter and supplier of natural gas). The Network Code is a set of rules that determine how users of the pipeline system cooperate with the system operator when seeking transportation services. The operator uses price signals generated through the flexibility mechanism to choose the balancing measures with the lowest cost to society.

Juris analyzes the four mechanisms used in physical gas markets, describes developments in the U.K.'s financial gas market, and describes pipeline capacity trading in primary and secondary markets and BGT's pricing of capacity and transportation services.

The most important issue today, says Juris, is whether industry participants can reach a consensus on how to enhance the existing framework to make markets more efficient. Development of the underdeveloped financial gas market will require cooperation between BGT and the Office of Gas Supply to give the International Petroleum Exchange access to BGT's electronic network, so that it can record and settle transactions. Both BGT and its customers will need to contribute time and resources to developing an efficient tariff structure for pipeline capacity and transportation services in the contract and tariff markets.

This paper - a product of Private Participation in Infrastructure Division, Private Sector Development Department - is part of a larger effort in the department to analyze issues arising from private participation in infrastructure. Copies of the paper are available free from the World Bank, $1818 \mathrm{H}$ Street NW, Washington, DC 20433. Please contact Sandra Vivas, room Q7-005, telephone 202-458-2809, fax 202-522-3481, Internet address svivas@worldbank.org. March 1998. (49 pages)

The Policy Research Working Paper Series disseminates the findings of work in progress to encourage the exchange of ideas about development issues. An objective of the series is to get the findings out quickly, even if the presentations are less than fully polished. The papers carry the names of the authors and should be cited accordingly. The findings, inierpretations, and conclusions expressed in this paper are entirely those of the authors. They do not necessarily represent the view of the World Bank, its Executive Directors, or the countries they represent. 


\title{
Market Development in the United Kingdom's Natural Gas Industry
}

\author{
Andrej Juris
}





\section{CONTENTS}

Pipeline System Operation

Costs in System Operation

System Operation under the Network Code

Natural Gas Markets

Physical Gas Market

Financial Gas Market

Capacity Markets

Primary Capacity Market

Secondary Capacity Market

\section{Conclusion}

\section{Appendix}

Structure and Regulation of the U.K. Natural Gas Industry

Notes

References

\section{Tables}

1. Size of the U.K. Gas Market, 1994-95

2. Spot Market Prices and Volumes at the Bacton Terminal, June-July 1996

3. On-System Trading, July 22-28, 1996

4. Trading and Prices in the Flexibility Market, July 19-28, 1996

Table A.1 U.K. Gas Price Index, Current Prices

Table A.2 U.K. Gas Price Index, Real Prices

Table A.3 Natural Gas Consumption, 1986-95

Table A.4 Natural Gas Production and Imports, 1986-95

\section{Boxes}

1. Participants in the U.K. Natural Gas Industry

2. Transition Costs of Opening Natural Gas Markets to Competition: The Case of British Gas Energy

\section{Figures}

1. Network Code Processes

2. Mechanisms for Natural Gas Trading in the U.K.

3. Argus Monthly Sell-Buy Index, October 1995-September 1996

4. Balancing under the Soft Landing Regime of the Network Code

5. Price Determination in the Flexibility Market with the Source of Imbalance a Change in Demand

6. Price Determination in the Flexibility Market with the Source of Imbalance a Change in Supply

7. Pipeline Capacity Booking and Trading

8. Capacity Resale by Auction

Figure A.1 Structure of the U.K. Natural Gas Industry

Figure A. 2 Index of Current Gas Prices, $1990=100$

Figure A.3 Index of Real Gas Prices, $1990=100$

Figure A.4 Natural Gas Consumption, 1986-95

Figure A.5 Natural Gas Production and Imports, 1986-95 

Deregulation and structural reforms in the natural gas industries of many countries have prompted questions about how far deregulation should go and whether markets in natural gas and pipeline transportation can function properly. The experience of the United Kingdom shows that markets can be successfully created in almost all segments of the natural gas industry, as long as the design of these markets takes into account the economic and technical characteristics of the industry. These characteristics include the multiproduct economies of scale that dominate pipeline transportation and the economies of scope between natural gas supply and transportation.

As the industry moves away from a vertically integrated structure, appropriate mechanisms to facilitate trading in gas markets and coordinate interactions between the pipeline system operator and pipeline users must substitute for operations once performed internally by the system operator. Such mechanisms support competition and efficiency in the natural gas industry and help optimize gas flows and transportation costs in the deintegrated natural gas industry. Once these mechanisms are in place, economic regulation can focus on markets characterized by natural monopoly, such as the primary market for pipeline capacity.

This paper shows how the U.K. government and industry participants have responded to the challenges created by the opening of the natural gas industry to competition. It concludes that the appropriate mechanisms for system operation and balancing and for natural gas and capacity trading are already in place as a result of cooperation between the government and industry participants.

The paper first describes the processes of the Network Code, a market-based method to balance the pipeline system and optimize transportation by British Gas TransCo (BGT), the transportation and storage arm of British Gas (the former publicly owned, monopoly transporter and supplier of natural gas). It then analyzes the mechanisms used in physical gas markets and presents an overview of developments in the financial gas market in the U.K.. Next it describes pipeline capacity trading in primary and secondary markets and the pricing of capacity and transportation services by BGT. Finally, it summarizes the lessons from market development in the U.K. natural gas industry.

\section{Pipeline System Operation}

The purpose of pipeline system operation is to optimize gas flows and minimize imbalances between gas intake and offtake. The main functions of system operation are:

- Intake of gas of agreed volumes and quality at injection, or entry, points.

- Transportation of gas through the pipeline system.

- Offtake of gas of agreed volumes and quality at delivery, or exit, points. 
- Maintenance of balance between intake and offtake.

- Maintenance of a specific pressure.

- Maintenance of a specific calorific value of gas.

These functions are carried out through the scheduling and central dispatch of gas flows. Typically, a system operator schedules gas flows and balances the system according to the supply and demand estimated on the day preceding the gas day. During the gas day the operator relies on a central dispatch unit to respond to system imbalances by adjusting pressure, rerouting gas flows, or curtailing intake or offtake in real time.

The industry structure determines the way in which the operator runs the system. In a vertically integrated industry the operator optimizes gas flows and minimizes imbalances internally. In a deintegrated industry it must coordinate these functions with other market participants. A set of rules for system operation and balancing is important in both industry configurations, but it is much more important in a deintegrated industry than in a vertically integrated one. If there are a large number of pipeline system users, coordination is required between them and the system operator, through "rules of the game" that determine nomination and scheduling of gas flows and balancing and operation of the system.

\section{Costs in system operation}

How the system is operated affects the costs faced by the system users for both transportation and system operation. The natural monopoly characteristics of transportation and the economies of scope between transportation and system operation mean that costs can be minimized only if there is just one system operator. But the lack of competition would mean that no market forces are acting as a check on prices, and an unregulated system operator would typically charge monopoly prices for transportation and system operation. Economic regulation of transportation services and capacity and a transparent set of rules for system operation help the regulator and users prevent such exploitation of market power by the system operator (for a discussion of economic regulation of transportation services and capacity see the section below on capacity markets).

System balancing is a complex operation that imposes costs on the system users. If a system user runs an imbalance, it imposes costs on the other users. The role of the system operator is to discourage such behavior by reflecting these costs in balancing penalties. But if the system runs an imbalance, the system operator implements balancing measures that impose costs on some or all users. The operator has much discretion in selecting these measures. To ensure that the selection is based on the costs of the measures, explicit rules are needed for sequencing the measures according to the situation. In addition, mechanisms are needed to expose the system operator to the costs of system balancing. 
One way to expose the system operator to such costs is through the pricing of transportation contracts. These contracts are priced according to the reliability of supply provided by the system operator. Thus interruptible transportation contracts are sold at lower prices than firm transportation contracts, because interruptible shipments are curtailed first, and firm shipments last, in the event of a system imbalance. Users purchase the contracts that match their needs for reliability of supply, paying a premium for more reliable transportation.

Another way to expose the system operator to the costs of balancing is by establishing a spot market for imbalances - the excess or missing gas in the system. The system operator can use the price signals generated by a spot market to compare the costs of system balancing measures with the cost of the gas needed to restore system balance, then decide whether to purchase or sell the missing or excess gas in the spot market or to curtail gas flows on the basis of the cost of each transaction. A spot market thus brings market forces to bear on the system operator. In addition, it allows an effective penalty to be imposed on users that cause a system imbalance, a penalty based on the spot price for the missing or excess gas. This price which reflects the market value of the imbalance, is an effective penalty because the price of a positive imbalance is typically lower than the price the users paid in the gas market, and the price of a negative imbalance typically higher.

\section{System operation under the Network Code}

The Network Code of British Gas TransCo is a set of rules for system balancing, capacity acquisition and trading, and gas transportation and trading in the pipeline system operated by BGT. ${ }^{1}$ And it is the legal document that forms the basis of the agreement between BGT and shippers regarding the operation and use of the pipeline system.

The Network Code facilitates cooperation among the participants in the unbundled, deintegrated gas industry in the U.K., requiring each participant is required to perform certain activities, or processes, that in the end lead to optimal system operation and balancing (for a description of the gas industry and its participants see box 1 and the appendix). Because coordinating these processes requires the exchange of a large amount of data, the participants communicate with one another through the U.K. Link, a computer system developed by BGT.

\footnotetext{
${ }^{1}$ This section draws from BGT 1996.
} 
The Network Code processes are performed in four stages, according to their position relative to the gas day, the day when actual transportation of gas takes place (figure 1). The gas day runs 24 hours, from 6:00 a.m. on the current day to 6:00 a.m. on the next day.

\section{Box 1: Participants in the U.K. Natural Gas Industry}

Delivery facility operators are the operators of the gas processing facilities at entry terminals. Public gas transporter is an operator of transmission pipelines under a license granted by Ofgas. At present BGT and several small transmission companies have public gas transporter licenses.

Storage managers are the operators of storage facilities. At present BGT is the only storage manager linked to the pipeline network.

Shippers are firms with a shippers license that buy gas from producers, sell it to suppliers, and contract a public gas transporter for transportation of the gas to consumers.

Suppliers are firms with a suppliers license that buy gas from shippers and then sell it to consumers. Suppliers do not deal directly with producers or public gas transporters. Many companies have both suppliers and shippers licenses.

The Office of Gas Supply (Ofgas) is the regulator of the ratural gas industry in the U.K.. Traders are firms that buy and sell natural gas in the spot market. Traders do not deal directly with public gas transporters or customers.

Allocation agents are the administrators of the entry points in the pipeline system. These agents act on behalf of shippers and calculate how much of the gas injected at a terminal belongs to each shipper. Then they inform a public gas transporter which calculates the transportation charges for each shipper.

Shippers' agents are authorized to carry out the Network Code processes on behalf of shippers. Top-up manager is a unit of BGT that ensures that enough gas is stored to meet demand in the event of severe weather during the following winter.

Shrinkage provider is a unit of BGT that is responsible for obtaining the gas needed to fuel compressors and balance any leakage in the pipeline system.

Source: BGT 1996. 
Figure 1 Network Code Processes

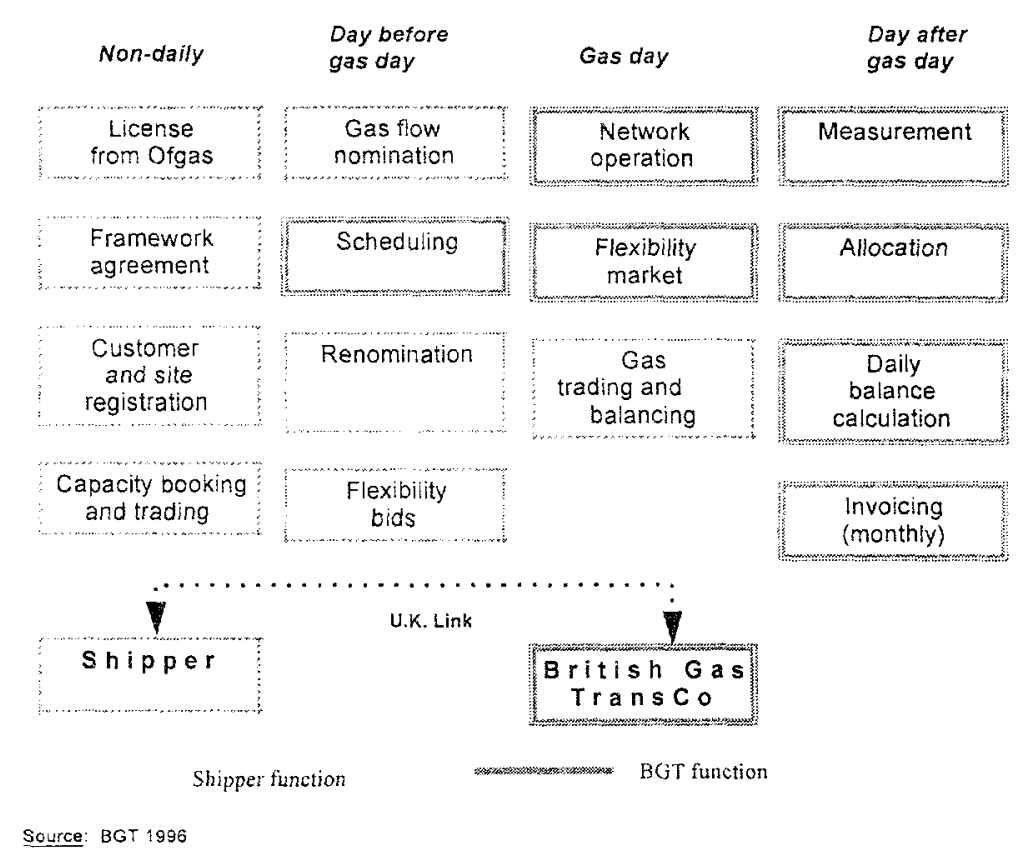

Stage 1: Non-daily processes, performed before the gas day

- Shippers must obtain a shippers license from Ofgas and then establish a framework agreement with BGT.

- Shippers purchase pipeline or storage capacity, or both, from BGT (capacity booking) or from other shippers in the secondary capacity market (capacity trading). BGT charges shippers for booked capacity monthly.

- Shippers register their customers and supply sites, or exit points, with BGT. Supply sites can be daily metered or non-daily metered. Typically, contract market customers have daily metered sites, and tariff markế customers non-daily metered sites.

\section{Stage 2: Processes performed on the day before the gas day}

- In the gas nomination process shippers inform BGT about the location, quantity, and calorific value of gas to be injected into and withdrawn from the system on the gas day (shippers can send their nomination up to one month in advance). Nomination must be finalized by 12:00 p.m. for withdrawal at daily metered sites, by 2:30 p.m. for use of storage, and by 3:00 p.m. for injection at the entry points. In the meantime BGT forecasts withdrawal at non-daily metered sites for each shipper and creates 
non-daily metered nominations by 2:00 p.m.. All shippers' nominations must be approved by BGT.

- On the basis of the approved nominations, BGT schedules the gas flows in the pipeline system to maintain safety and reliability of supply and to minimize costs. If the system cannot transport all nominated gas, BGT contacts shippers and asks for revised nominations.

- Renominations can be made between 6:00 p.m. on the day before the gas day and 3:59 a.m. on the current day.

- Shippers able to adjust their supply and demand according to the expected system price post their flexibility bids for selling or buying gas from BGT on the U.K. Link. Flexibility bids become available to BGT at about 6:00 p.m. (see the section below on the flexibility mechanism).

- Shippers trade gas in the on-system market and include information about the trade in their nominations or renominations (see the section below on on-system trading).

Stage 3: Processes performed during the gas day

- BGT operates the network according to the schedule and responds to any problem in the system through central dispatch of entry and exit points and the gas flows.

- BGT monitors the system balance. If the system runs an imbalance, BGT buys or sells the missing or excess gas in the flexibility market. If it cannot eliminate an imbalance through the flexibility mechanism, it uses available storage facilities or, in serious cases, asks shippers to stop shipments to interruptible sites. ${ }^{2}$ In an emergency BGT issues flow orders ${ }^{3}$.

- Shippers are responsible for maintaining a balance between their intake and offtake according to their nominations. If they run an imbalance, they can avoid penalties by trading in the on-system market.

Stage 4: Processes performed on the day after the gas day

- BGT collects data about the volume and calorific value of gas at entry and exit points and in storage. At 4:00 p.m. metering data become available for the allocation process.

\footnotetext{
${ }^{2}$ BGT's choice of interruptible sites must depend entirely on operational necessity. But on average over the year, all shippers with interruptible sites must be treated equally.

${ }^{3}$ Flow orders are orders issued by pipeline companies that require shippers to inject or withdraw natural gas at a specific point to ensure continued flow of natural gas through the system during an emergency.
} 
- The allocation process allocates the gas injected and withdrawn at specific sites among the shippers. This task is performed by an allocation agent at entry points and by BGT at daily metered and non-daily metered exit sites and storage. Shippers receive allocation data for review.

- Each shipper's balance is calculated on the basis of the allocation data. ${ }^{4}$ Shippers with imbalances above a specified tolerance level are charged an imbalance penalty. In addition, they are charged or credited for gas that is above the tolerance level, at a price equal to the last accepted flexibility bid in the flexibility market.

- BGT uses the allocation data to calculate the commodity charges. It adds to these charges capacity overrun penalties, if applicable, and credits or charges for the flexibility bids accepted.

- Finally, BGT produces a detailed monthly invoice for each shipper that includes all applicable charges and credits and sends it to the shipper through the U.K. Link.

The final rule of the Network Code is that BGT cannot earn positive or negative profits from maintaining system balance. So at the end of each month BGT sums up all receipts and payments for the flexibility bids accepted and the imbalance and scheduling charges and then credits or charges a share of the net sum to each shipper in proportion to the amount of gas it shipped during that month.

\footnotetext{
${ }^{4}$ Allocation data are finalized within seven days after the gas day. If changes occur, the balance is
} recalculated and adjustment is made in the next invoice. 


\section{Natural Gas Markets}

The unbundling of gas supply and transportation and the opening of natural gas markets to competition have created new requirements relating to how natural gas is traded and how market participants interact. System operation rules guide the interactions between gas shippers and the monopolistic gas transporter. But the industry structure and trading mechanisms determine the efficiency of gas markets.

An efficient natural gas market performs three functions:

- It aggregates supply and demand to determine system demand and supply curves.

- It facilitates market clearing to determine the market price of natural gas.

- It signals the market value of gas.

Market aggregation is achieved by concentrating trading among producers, traders, and shippers at one or several trading points. These trading points can be market centers, typically located at the major pipeline interconnection or at the major entry point to the high-pressure transmission system. In the U.K. the onshore terminals where producers deliver their gas to BGT's pipeline network have become the trading points.

Market clearing is facilitated by trading mechanisms - bilateral trading, brokerage, spot markets, and auctions. Which of these mechanisms is used depends on the characteristics of supply and demand as reflected in the dimensions of gas contracts - typically time and location of delivery, pressure and calorific value of gas, security of supply, and, of course, the unit price of gas. Participants in the U.K. gas markets use all four trading mechanisms.

Price signaling is facilitated by the collection and dissemination of information about prices and trading volumes by reporting and consulting agencies, journals, and newsletters. The reporting of this information enables market participants to choose trading and consumption strategies according to market signals. In the U.K. several firms regularly report spot market prices and volumes, including PH Energy Analysis and Argus Petroleum. At present there is no statistical or panel reporting of spot market prices.

Natural gas markets allow the trading of long-, medium-, and short-term natural gas. While long- and medium-term gas contracts are more typical for the integrated gas industry, short-term gas contracts are important in the deintegrated gas industry because of market participants' need to achieve physical balance between demand and supply in a short time frame (typically between one day and one month). Thus system balancing affects how natural gas is traded. In the U.K. the balancing requirements of the Network 
Code have led to two forms of gas trading: on-system trading and the flexibility mechanism.

Short-term gas trading is conducted using bilateral trading, brokerage, auction, and spot market mechanisms. Bilateral trading, typically in which buyers and sellers negotiate supply conditions on a bilateral basis, develops first. As the volume of trading increases, bilateral trading becomes inefficient because markets become nontransparent and trading imposes high transaction costs on market participants. Bilateral trading is therefore replaced by brokerage.

Brokerage is an advanced bilateral trading model in which brokers, or traders, trade on behalf of buyers and sellers. Brokers aggregate the demand and supply of their clients and trade among themselves or with other market participants. As trading volume increases, market participants need to concentrate trading at one or several trading points to reduce transaction costs, and brokerage trading evolves into spot market trading.

The development of a spot market is typically followed by the development of risk management instruments. Because spot market prices reflect system short-run marginal costs of gas and the opportunity costs of capacity, they tend to be volatile, and the inherent price risk is often very high for many market participants. This leads to demand for risk diversification and, ultimately, to the development of a financial gas market where risk-minimizing financial instruments are traded. These markets can be organized or not, depending on the ability of institutions to respond to market needs. Initially, financial institutions offered mostly swaps to customers on an individual basis. Trading of standardized financial gas contracts in the U.K. started on January 31, 1997, when the International Petroleum Exchange introduced natural gas futures contracts for delivery at the National Balancing Point in BGT's pipeline system.

Auctioning is typically used for efficient trading of goods when one player dominates supply or demand. In the U.K. natural gas industry, gas auctioning is conducted by BGT in trading system imbalances. The trading rules are determined by the Network Code in order to prevent abuse of BGT's monopoly in this market.

\section{Physical gas market}

Although British Gas has historically dominated the physical gas market, it has rapidly been losing market share since deregulation of gas supply. In the past five years its monopoly has been eroded by competition in the contract market. Its gas trading and supply arm, British Gas Energy (BGE), now has about a 33 percent share in that market, but still has a monopoly in the tariff market (table 1; for a discussion of the distinction between contract and tariff markets, and end-use consumption and prices, see the appendix). Taken together, these two positions give BGE about a 67 percent share in the overall gas market in the U.K.. Although BGE faces competition from about 40 suppliers in the contract market, its overall market share is unlikely to change substantially. On the 
other hand, it is estimated that it will lose about 25 percent of its tariff market share after gas supply to the tariff market is opened to competition in 1998 (Royle 1996).

Table 1 Size of the U.K. Gas Market, 1994-95 (millions of therms)

\begin{tabular}{lccc} 
Market & 1994 & 1995 & $\begin{array}{c}\text { BGE's share } \\
1995 \text { (percent) }\end{array}$ \\
\hline Tariff market & 11,440 & 11,800 & 100 \\
Contract market & 10,780 & 11,200 & 33 \\
$\quad$ Firm supply & 5,720 & 5,900 & 15 \\
Interruptible supply & 3,300 & 3,300 & 50 \\
Power generation supply & 1,760 & 2,000 & 38 \\
Total gas supply & 22,220 & 23,000 & 67 \\
\hline
\end{tabular}

Source: Royle 1996

The deregulation of retail markets, an open access policy, and the unbundling of British Gas's supply and transportation have led to the development of short-term gas trading. Until recently most gas was sold under long- and medium-term contracts between British Gas and producers or consumers. After deregulation market participants had to balance their supply and demand in the short term and thus needed an effective way to trade short-term gas. That led to the development of spot markets in entry terminals and in BGT's pipeline system. At present, there are four mechanisms for trading natural gas in the U.K.: bilateral contracts, spot markets, on-system trading, and the flexibility mechanism (figure 2). 


\section{Figure 2 Mechanisms for Natural Gas Trading}

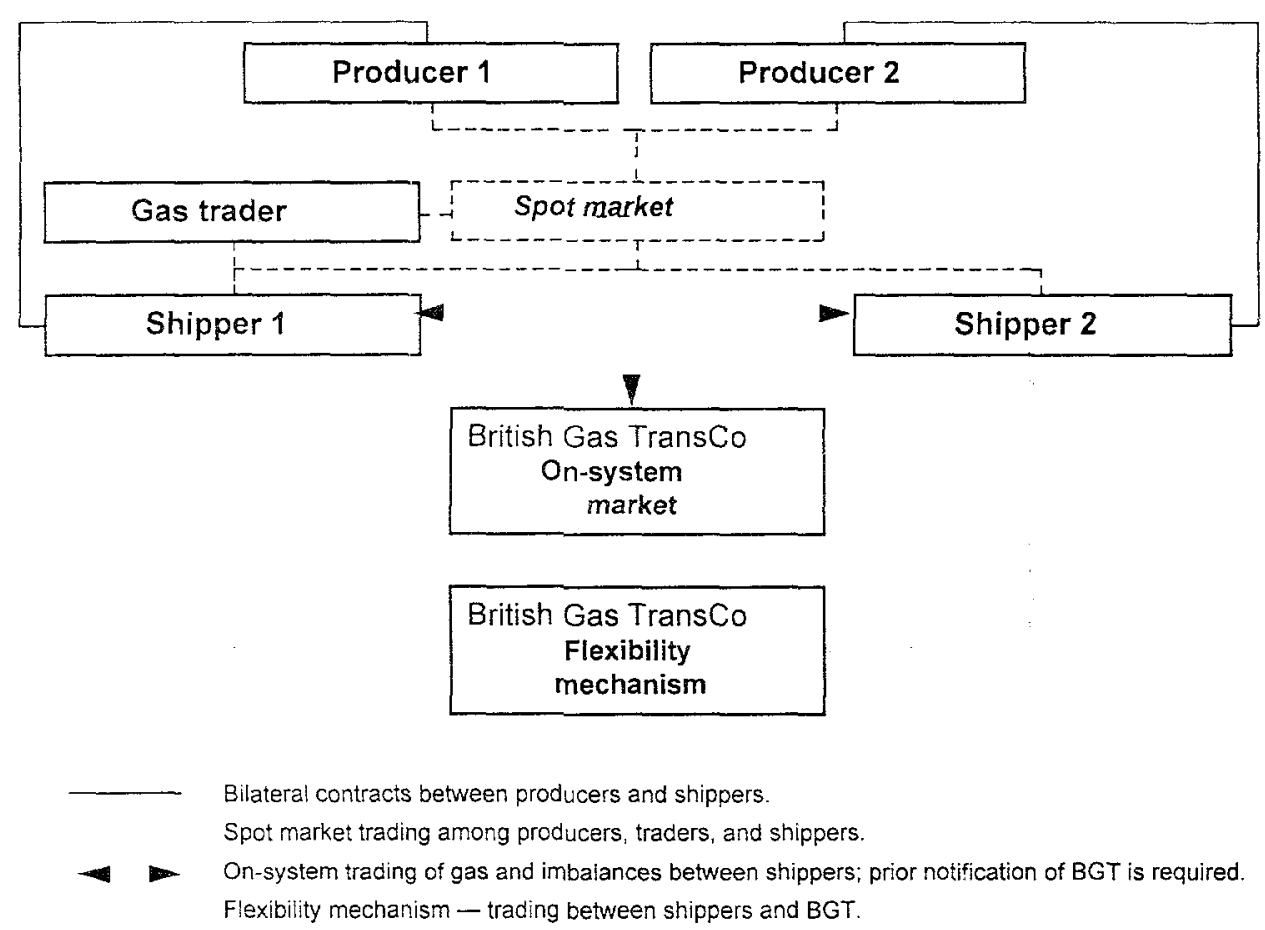

Source: Author's compilation

\section{Bilateral contracts}

The traditional way of trading natural gas in the U.K. is through bilateral contracts, medium- and long-term natural gas supply contracts, between producers and shippers. The provisions in these contracts vary widely, depending on the characteristics of the parties' demand and supply. Parties typically specify the total volume of gas covered by the contract; the unit price of the gas, which can be fixed or linked to the price of other fuels (such as oil); and the financial settlement.

Long-term contracts specify delivery of gas for a period longer than one year, mediumterm contracts for a period between three months and one year. A typical example of a long-term contract is a take-or-pay contract under which the buyer agrees to pay regularly for a specified volume of gas regardless of whether it actually takes the entire amount. The U.K. alternative to the take-or-pay contract is a depletion contract, under which the buyer finances a share of the producer's field development costs in exchange for future gas deliveries.

Historically, bilateral supply contracts were concluded between British Gas and its customers: British Gas acquired gas from producers at the onshore terminals and sold it 
to customers at consumption sites. But the opening of natural gas supply to competition has multiplied the contractual relations between producers and suppliers. As more and more gas has become available for independent suppliers, trading has gradually concentrated where producers and suppliers have the best access to the gathering and transmission pipeline systems. Bilateral supply contracts are now based on delivery at the Bacton and St. Fergus terminals. And since the introduction of the Network Code, bilateral contracts with delivery at the national balancing point have developed (see the section below on on-system trading).

The opening of natural gas markets to competition often involves transition costs for incumbent firms. One example of such costs is the investment necessary to fulfill the regulator's requirement to secure reliable supply for all consumers in the franchise area, an investment that becomes useless in a competitive market. Another is the liability arising from contracts that are not fulfilled because the regulator has altered the contractual relations. A regulator might allow cancellation of long-term contracts between suppliers and consumers to promote development of a spot market, for example, British Gas Energy will face such transition costs as a result of the deregulation of the tariff market in 1998 (box 2).

\footnotetext{
Box 2 Transition Costs of Opening Natural Gas to Competition: The Case of British Gas Energy

Long-term bilateral contracts often become a burden for an incumbent supplier after the opening of natural gas markets to competition. The incumbert often becomes stuck with takeor-pay contracts concluded under an "obligation-to-serve" regulatory regime, as many of its customers switch to competing suppliers.

British Gas Energy holds take-or-pay obligations to purchase about 4.6 billion cubic feet a day (bcfd) of gas from producers, but it can sell only about 4.35 bcfd in the consumer market. This results in an estimated surplus of $0.25 \mathrm{bcfd}$, or 5 percent of total take-or-pay obligations, assuming that BGE maintains a 90 percent share in the tariff market in 1998. The BGE's liability from this surplus amounts to about GBP 528 million on an after tax, present-value basis, assuming that BGE maintains a 90 percent share in the tariff market in 1998.

Although BGE's surplus is not a significant volume, it represents about 30 percent of recent spot market volumes. So if BGE delivers its surplus gas to spot markets, it will push down spot market prices, enabling BGE's competition to attract more customers through lower prices. Eventually, BGE may lose more than 10 percent of its market share, which would increase its take-or-pay liabilities.

Source: Royle 1996.
} 


\section{Spot market trading}

Spot markets have developed at the onshore terminals of BGT's pipeline network as a result of the increasing need to balance supply and demand in the short term. ${ }^{5}$ Four main factors are behind the development of spot market trading in the U.K.: ${ }^{6}$

1. Introduction of the $90: 10$ rule in 1989. This rule prohibits British Gas from purchasing more than 90 percent of the gas from any field. After it was introduced, producers started to market their gas to independent gas suppliers, which competed with British Gas in the contract market. Producers initially sold gas under medium- or long-term contracts. But as changing demand and supply conditions led to a need to balance gas requirements in the short term, they started selling gas on a short-term basis.

2. Ofgas order to British Gas to release gas to competitors in 1991. Between 1992 and 1995 British Gas made about 4.9 billion cubic meters of gas (this is total volume over the whole period) available to competing suppliers through sale in spot markets.

3. Oversupply by independent suppliers. Some suppliers committed themselves to 100 percent take-or-pay contracts but could not find customers for their gas. They took the surplus gas to spot markets for resale.

4. Delay in the start-up of three power stations. This delay led to an estimated demand loss of 6.2 million cubic meters a day, or 3 percent of the average daily demand. Stuck with the surplus gas, producers took it to spot markets.

Trading in a spot market is done on a bilateral basis, between producers and shippers, or on a brokerage basis, with traders often acting as intermediaries. In the U.K. spot market trading started as a bilateral telephone market in 1989-90 between producers and suppliers (Roeber 1996). The nature of the trading has not changed substantially except for the entry of traders and the higher volumes of trading. Producers, shippers, and traders "shop around," arranging for terms that best suit their needs.

Five types of natural gas contracts are traded in the U.K. spot markets:

- Day-ahead gas - for delivery on the next day.

- Balance gas - for delivery on a daily or weekly basis.

- Monthly gas - for delivery during a specified calendar month.

\footnotetext{
${ }^{5}$ There are six entry terminals in the U.K., but only two of them, Bacton and St. Fergus, have developed into major spot markets.

${ }^{6}$ The data in this section are drawn from Royle 1996.
} 
- Quarterly and annual gas - for delivery during a specified quarter or year.

- Time spread gas - for delivery against gas under contract for a different time of delivery.

The products most commonly traded in the U.K. spot markets are day-ahead and monthly gas contracts for delivery to the Bacton or St. Fergus terminals.

The U.K. spot markets are still generally thin, illiquid, and volatile. Trading volume ranges from 2 million to 8 million therms a day, 5 to 10 percent of the total daily supply. Prices vary accordingly - ranging from 9 to 14 pence a therm (table 2 and figure 3 )

Traded volumes and prices are reported by the media or specialized newsletters, such as British Spot Gas Markets, published by PH Energy Analysis, and European Natural Gas Daily, published by Petroleum Argus. British Spot Gas Markets introduced the Heren Index, which is the weighted average price of traded gas contracts for delivery in a particular month. The index, which is based on volume and price information collected from traders, is an indicator of the market price of short-term gas and is increasingly used as a price reference in bilateral contracts (Powel 1996).

Table 2 Spot Market Prices and Volumes at the Bacton Terminal, June-July 1996

\begin{tabular}{lrr} 
Indicator & June 1996 & July 1996 \\
\hline Heren Index (pence per therm) & 12.1275 & 9.6546 \\
Number of transactions & 38 & 35 \\
Total volume (millions of therms & 2.278 & 2.072 \\
per day) & & \\
Lowest price (pence per therm) & 10.50 & 9.00 \\
Highest price (pence per therm) & 13.575 & 11.5 \\
Smallest volume (therms per day) & 18,000 & 15,000 \\
Largest volume (therms per day) & 250,000 & 300,000 \\
\hline
\end{tabular}

Source: The Heren Index, July 1996

The most important issue in the further development of spot markets in the U.K. is the need for a standardized gas contract. An efficient short-term market should facilitate the pricing of gas according to the system short-run marginal cost of gas. A short-term gas contract has fewer parameters than a long-term gas contract, which includes a number of delivery characteristics in addition to price. A standardized short-term contract specifying a delivery to a major terminal or an interconnection in the pipeline system therefore improves the efficiency of trading short-term gas. The introduction of the "on-system" market at the National Balancing Point in BGT's pipeline system provides a "systemwide" trading point for such a contract. This is complemented by the activities of the International Petroleum Exchange (IPE) to launch the trading of standardized physical and financial gas contracts at the National Balancing Point. The IPE has succeeded in 
developing a commercially viable natural gas futures contract, but the development of a short-term gas contract has been postponed due to communication problems between the IPE and BGT.

Figure 3 Argus Monthly Sell-Buy Index, October 1995-September 1996

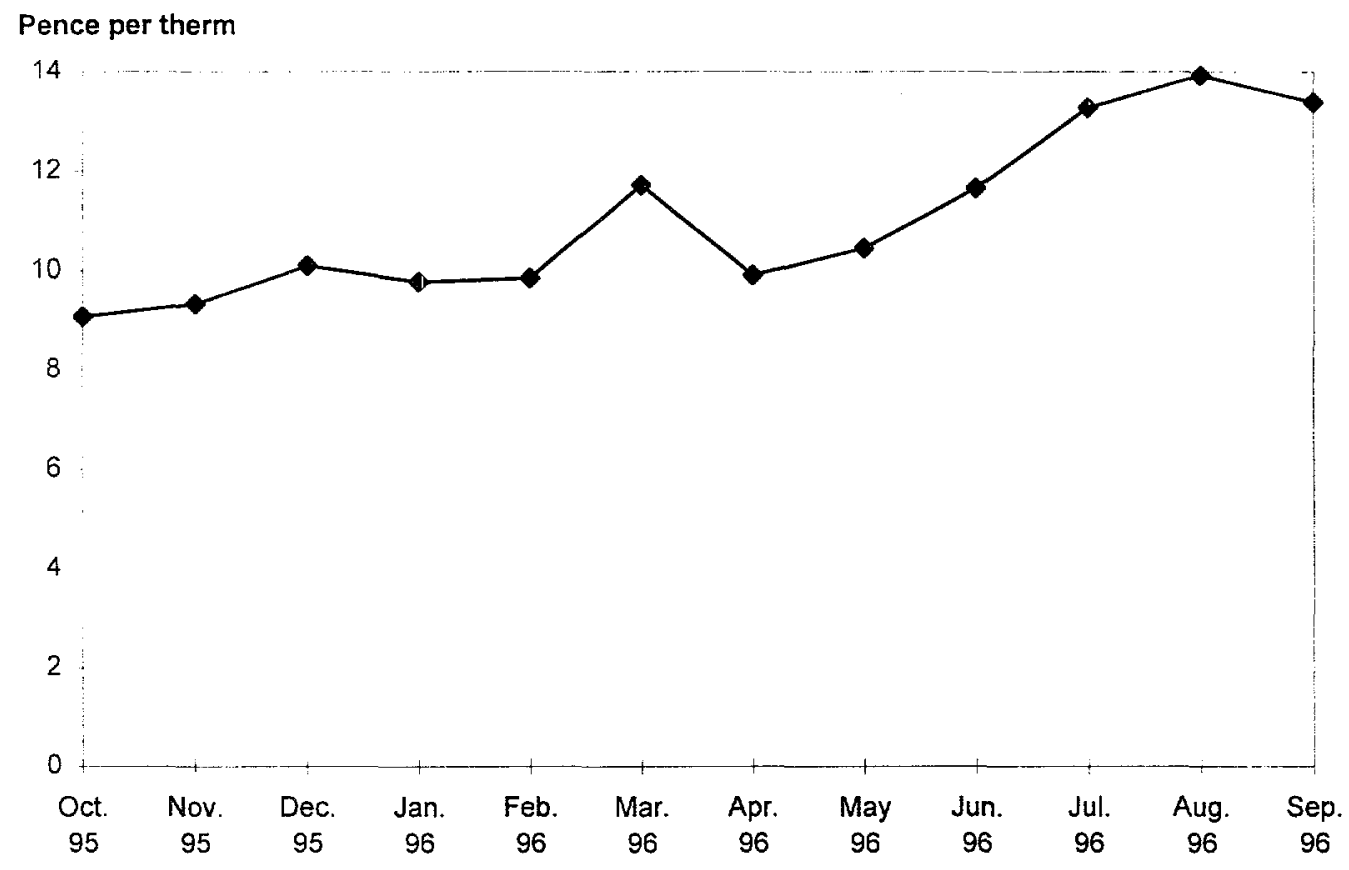

Source: Petroleum Argus data 


\section{On-system trading}

The on-system trading is basically trading in a spot market located at an imaginary notional point in the pipeline system. Shippers use their reserved pipeline capacity to deliver natural gas to the notional point where they sell it to interested buyers. Buying shippers then use their pipeline capacity to transport natural gas from the notional point to a desired location. The pipeline system operator, which keeps track on traded volumes and provides transportation services, facilitates completion of transactions.

The on-system market in the U.K. facilitates trading of natural gas at the National Balancing Point (NBP), a notional point in BGT's pipeline network at which BGT balances its high pressure pipeline system. Transactions typically involve shippers which own entry and exit pipeline capacity, and are facilitated by BGT's nomination process under the Network Code. A shipper with entry capacity to the NBP sells natural gas to a shipper with exit capacity from the NBP. After the two shippers agree on the conditions of trade, they nominate their gas flows, specifying the other party as the exit and entry point. If the two nominations match in BGT's system schedule, BGT approves the trade and the transaction can be completed.

Physical and financial flows of a transaction in the on-system market are different. The gas withdrawn from BGT's system by the buying shipper is often different from the gas injected by the selling shipper, because BGT directs gas flows subject to system optimization and does not follow contractual links. The only requirement for BGT is that it deliver the same quantity and quality of gas nominated by the contractual parties. Financial settlement of the transaction involves only the shippers; BGT does not participate.

The on-system market has become popular among gas traders in the U.K. because of its central location, accessibility, and low transaction costs. The on-system trading is becoming increasingly robust and liquid, as the liberalization of the U.K. gas market advances. Shippers use the on-system market to trade a whole variety of natural gas contracts, which are much the same as those traded in a spot market:

- Day-ahead gas is a common product in all spot markets. The delivery period is the next gas day; and the gas is used for daily balancing and price arbitrage. In an example of a day-ahead gas trade, on September 24, 1996, 25,000 therms of gas for delivery on the next gas day (between 6:00 a.m. September 25 and 6:00 a.m. of September 26) were sold for 13.1 pence per therm (see line 9 of table 3).

- Balance gas restores the shipper's balance between supply and demand in a particular period. The delivery period ranges from one day to one month, depending on the shipper's needs. In an example of a balance gas trade, on July 25, 1996, 50,000 therms a day of balance gas for delivery over the remaining days of July were sold for 13 pence per therm (see line 5 of table 3 ). 
- Short-and medium-term gas is sold or resold to suppliers, with the period of delivery ranging from one month to one year. In one such transaction 100,000 therms a day of short-term gas were traded on July 25, 1996, for delivery in October 1996 (see line 6 of table 3). Similarly, two blocks of 25 therms a day of medium-term gas were traded on July 24 , one for delivery in the fourth quarter of 1996 and the other for delivery in the 12 months starting October 1996 (see lines 3 and 4).

- Time spread gas represents an exchange of gas contracts with different times of delivery. Shippers settle the price difference on the basis of their projection of the price of the gas. On July 26, 1996, shippers exchanged two gas contracts for delivery of 25,000 therms a day of gas in August and October (see line 8 of table 3). They agreed that the price of the contracts was identical, based on the prevailing spot market prices.

Table 3 On-System Trading, July 22-28, 1996

\begin{tabular}{lllrr} 
& Day of trade & Period of delivery & $\begin{array}{c}\text { Volume } \\
\text { (thousands of therms a day) }\end{array}$ & $\begin{array}{c}\text { Price } \\
\text { (pence per therm) }\end{array}$ \\
\hline 1 & July 22 & Sept. 1-30 & 25 & 12.95 \\
2 & July 23 & Aug. 1-31 & 25 & 13.15 \\
3 & July 24 & Fourth quarter, 1996 & 25 & 13.525 \\
4 & July 24 & Oct. 1996-Sept. 1997 & 25 & 12.95 \\
5 & July 25 & July balance & 50 & 13.00 \\
6 & July 25 & Oct. 1-31 & 100 & 13.20 \\
7 & July 26 & Aug. 1-31 & 25 & 13.30 \\
8 & July 26 & Time spread & 25 & no price \\
& & Aug. vs. Oct. & & difference \\
9 & September & Day ahead & 25 & 13.1 \\
& 24 & & & \\
\hline
\end{tabular}

Source: PH Energy Analysis, British Spot Gas Markets, Petroleum Argus, European Natural Gas Daily.

\section{The flexibility mechanism}

The flexibility mechanism provides a framework for trading gas imbalances in BGT's pipeline network. Its primary purpose is to eliminate system imbalances caused by the deviation of shippers' gas injections and withdrawals from the approved schedule. BGT uses an auction mechanism to buy gas from or sell it to shippers in order to restore system balance. The flexibility mechanism thus effectively establishes a spot market - the flexibility market - that is much like the on-system market, except that trading takes place between BGT and shippers rather than among the shippers. Shippers bid volumes and prices, and BGT selects the bids that minimize the cost of restoring system balance. Ideally, competition among shippers should lead to bids that reveal the true system short- 
run marginal cost of gas, so that the price of gas in the flexibility market reflects the true market value of gas.

Transactions in the flexibility market are carried out through an auction because of BGT's monopoly or monopsony position as a seller or buyer of gas. The auction is guided by the Network Code and Ofgas. BGT operates the system on a nonprofit basis and so does not directly benefit from transactions in the flexibility market. Its incentive is thus to restore system balance rather than to speculate in the flexibility market.

Operation of the flexibility mechanism The flexibility mechanism operates as follows: ${ }^{7}$

- Shippers decide to sell gas to or buy it from BGT, depending on their estimates of system supply and demand and the price of gas. ${ }^{8}$ If a shipper expects a system imbalance on the next gas day and has some flexibility in adjusting its own portfolio of supply and demand contracts, it posts a flexibility bid on the electronic network. A flexibility bid can be for a "system sell" or a "system buy," depending on the kind of system balance expected. (The transactions in the flexibility market are always considered from the point of view of the system.). A typical flexibility bid specifies the type of bid, the date, the quantity and calorific value of gas, the injection or withdrawal points, the duration of the implementation of the offer, and the price per kilowatt-hour. Shippers can offer alternatives to their bid or withdraw it at any time except when the bid is being evaluated or after it has been accepted. Shippers can also see other bids but not who posted them.

- The list of bids becomes available to BGT at 6:00 p.m. on the day preceding the gas day. If a system imbalance occurs, BGT accepts the best bid, typically the one with the best price. (Other parameters considered are time, location of injection and entry points, and duration of implementation of the offer relative to the same parameters of the system imbalance.) That means that BGT accepts the lowest-price bid for a system buy and the highest-price bid for a system sell. The price of the last accepted bid becomes the system marginal price. BGT then notifies the successful bidders, who must implement the offers. If shippers fail to comply, they incur scheduling and imbalance penalties. All unaccepted flexibility bids become redundant at 4:00 a.m. on the current day. Transactions in the flexibility market are settled in a subsequent monthly invoice.

The flexibility mechanism was introduced as part of the Network Code in April 1996. The Network Code requires all shippers to keep a daily balance between injected and withdrawn gas within a certain tolerance. If shippers exceed their daily balance, they are

\footnotetext{
${ }^{7}$ This discussion of the flexibility's mechanism's operation draws from BGT 1996.

${ }^{8}$ Changes in supply and demand cause changes in the injections and withdrawals of individual shippers, resulting in system imbalance and action by BGT in the flexibility market. If the system runs a positive imbalance, BGT must sell the extra gas - a "system sell" - to restore system balance. If the system runs a negative imbalance, BGT must purchase the missing gas - a "system buy." The price for a system sell is lower than the prevailing spot market price, while the price for a system buy is higher.
} 
charged an imbalance penalty. In addition, they receive credit or are charged for the gas withdrawn or injected in excess of the tolerance. A unit price of this gas is equal to the system marginal price.

The transition from monthly to daily balancing imposed substantial requirements on shippers. To phase in this change, the Network Code operated under a "soft landing" regime between April and September 1996. This regime allowed shippers to exceed their daily balance by 100 percent of the daily average of their deliveries and offtakes during the previous 30 days. The daily imbalance outside this tolerance was cashed out at the system marginal price. At the end of the month, if the monthly imbalance (the cumulative daily imbalances) did not exceed three times the tolerance level, it was cashed out at the system average price, equal to the average price of all accepted flexibility bids during the last 30 days. If the monthly imbalance was above the tolerance, the imbalance was cashed out at the system marginal price (figure 4 ).

\section{Figure 4 Balancing under the Soft Landing Regime of the Network Code}

Daily imbalance tolerance

Monthly imbalance

Daily Imbalance

Monthly imbalance tolerance)

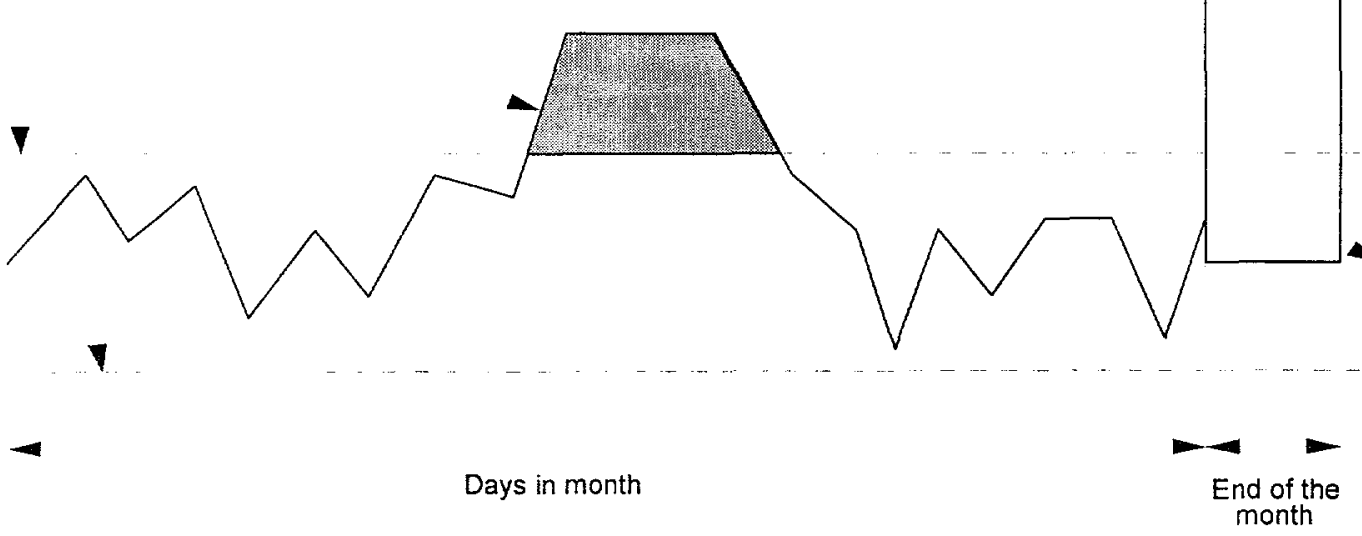

Source: Gas Matters, March 1996

Note: The daily imbalance is equal to the difference between offtakes and deliveries on the gas day. It is cashed out at the system marginal price if it exceeds daily imbalance tolerance; otherwise it is cashed out at the system average price. The daily imbalance tolerance is based on the average of the last 30 days of deliveries and offtakes. The monthly imbalance is equal to the cumulative daily imbalance at the end of the month. It is cashed out at the system marginal price if it exceeds the monthly imbalance tolerance; otherwise it is cashed out at the system average price. The monthly imbalance tolerance is equal to three times the daily imbalance tolerance. 
Evaluation of the flexibility mechanism The flexibility mechanism facilitates real-time, market-based reactions by the system operator to a system imbalance. BGT's ability to monitor the system and quickly identify the source, size, and location of an imbalance at any given moment allows it to determine an appropriate response. The price signals generated by the flexibility market indicate the cost-minimizing way to restore system balance. Based on the cost of gas as revealed by the flexibility bids, BGT can decide whether to use the flexibility mechanism to restore balance or to curtail shipments instead.

The flexibility mechanism effectively imitates a spot market in order to facilitate trading of day and swing gas ${ }^{9}$ in form of gas balances. Such gas is often lacking in spot markets, where the typical product is month gas. Trading in the flexibility market occurs only if the system is in an imbalance caused by the imbalances of individual shippers. These individual imbalances are caused by a change in supply or demand that induces a shipper to alter its injection and withdrawal schedule from the nominated one. At the same time, the change in supply or demand causes the market value of gas to deviate from the spot market price. BGT uses the flexibility mechanism to restore system balance and discover the actual market value of gas. Flexibility bids reveal the system short-run marginal cost of gas, and the market value of gas is equal to the system marginal price determined in an auction.

Shippers are willing to sell gas to the system only if the market value of gas is above the spot market price and to buy gas only if the market value is below that price. Consequently, shippers with imbalances realize the market price for the gas that is above the tolerance level. The system marginal price for a system sell therefore should be below the spot market price, while that for a system buy should be above the spot market price. This gives a premium to selling or buying shippers and imposes a penalty on shippers with imbalances. An overview of price determination in the flexibility market is given in figures 5 and 6.

\footnotetext{
${ }^{9}$ Swing gas is very-short term gas delivered on an hourly basis.
} 
Figure 5 Price Determination in the Flexibility Market with the

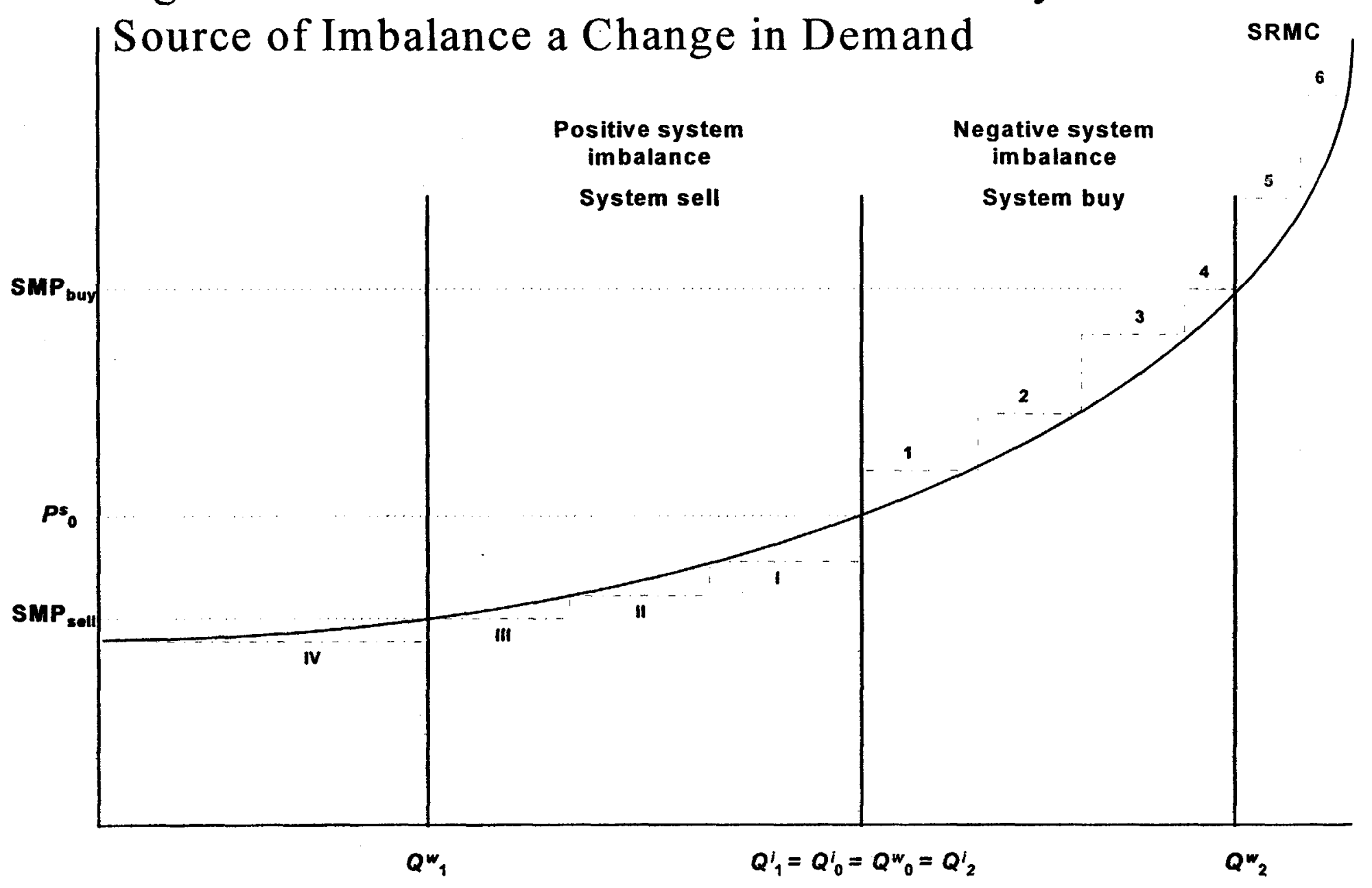


SRMC System short-run marginal cost of gas.

Situation on the day before the gas day

$P_{0}^{s} \quad$ Spot market price of gas with delivery on the gas day (day-ahead gas.)

$Q^{i}, Q^{w} \quad$ The quantity of gas nominated for injection into and withdrawal from BGT's pipeline system according to the approved schedule for the gas day. The system must be in balance: $Q^{i_{0}}=Q^{w_{\mathrm{o}}}$.

I-IV, 1-6 Flexibility bids for a system sell and a system buy.

\section{Situation on the gas day}

Case 1: Positive system imbalance - system sell

$Q^{w_{1}}<Q^{w_{0}} \quad$ The quantity of gas withdrawn from the system is below the nominated quantity because of an unexpected decrease in the demand for gas. Shippers are unable to react in real time, so the quantity of gas injected into the system is equal to the nominated quantity $\left(Q^{i}{ }_{1}=Q_{\mathrm{o}}^{i}\right)$.

$Q^{i}{ }_{1}-Q^{w_{1}} \quad$ The difference between the quantities of injected and withdrawn gas is equal to the size of the system imbalance, which is positive because $Q_{1}^{i}>Q^{w_{1}}$. BGT must sell the excess gas in the flexibility market to restore system balance. BGT accepts flexibility bids I-III.

$\mathrm{SMP}_{\text {sell }} \quad$ The system marginal price of gas sold by BGT to winning bidders. It is equal to the price of the last accepted flexibility bid.

Case 2: Negative system imbalance - system buy

$Q^{w_{2}}>Q^{w_{\mathrm{o}}} \quad$ The quantity of gas withdrawn from the system is above the nominated quantity because of an unexpected increase in demand for gas. Shippers are unable to react in real time, so the quantity of gas that is injected into the system is equal to the nominated quantity $\left(Q_{2}^{i}=Q_{0}^{i}\right)$.

$Q_{2}^{i}-Q_{2} w_{2} \quad$ The difference between the quantities of injected and withdrawn gas is equal to the size of the system imbalance, which is negative because $Q_{2}^{i}<Q^{w}{ }_{2}$. BGT must buy the missing gas in the flexibility market to restore system balance. BGT accepts flexibility bids 1-4.

$\mathrm{SMP}_{\text {buy }} \quad$ The system marginal price of gas bought by BGT from winning bidders. It is equal to the price of the last accepted flexibility bid. 
Figure 6 Price Determination in the Flexibility Market with the Source of Imbalance a

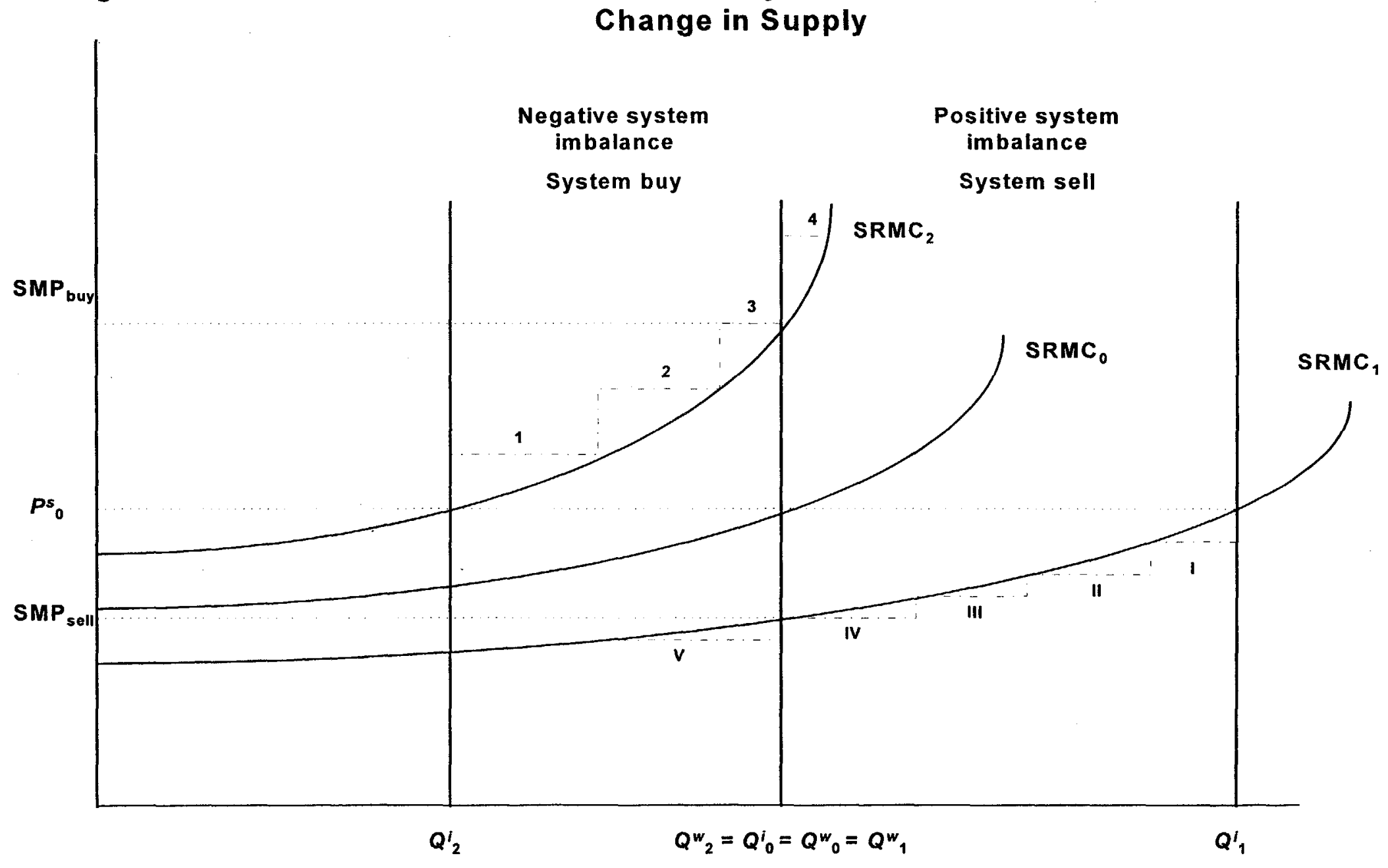




\section{Situation on the day before the gas day}

$\mathrm{SRMC}_{0} \quad$ System short-run marginal cost of gas.

$P_{0} \quad$ Spot market price of gas with delivery on the gas day (day-ahead gas).

$Q_{0}^{i}, Q^{w} \quad$ The quantity of gas nominated for injection into and withdrawal from BGT's pipeline system according to the approved schedule for the gas day. The system must be in balance: $Q^{i}=Q^{w}$.

I-V, 1-4 Flexibility bids for a system sell and a system buy.

\section{Situation on the gas day}

Case 1: Positive system imbalance - system sell

SRMC The SRMC shifts outward because of a positive gas supp'y shock.

$Q_{1}^{i}>Q_{\text {o }}^{i} \quad$ The quantity of gas injected into the system is above the nominated quantity because of an unexpected increase in the supply of gas. Consumers are unable to change consumption in real time, so the quantity of gas withdrawn from the system is equal to the nominated quantity $\left(Q^{w_{1}}=Q^{w_{0}}\right)$.

$Q_{1}{ }_{1}-Q^{w_{1}} \quad$ The difference between the quantities of injected and withdrawn gas is equal to the size of the system imbalance, which is possible because $Q_{1}^{i}>Q^{w}{ }_{1}$. BGT must sell the excess gas in the flexibility market to restore system balance. BGT accepts flexibility bids I-IV.

SMP $_{\text {sell }} \quad$ The system marginal price of gas sold by BGT to winning bidders. It is equal to the price of the last accepted flexibility bid.

Case 2: Negative system imbalance - system buy

$\mathrm{SRMC}_{2} \quad$ The system SRMC shifts upward because of a negative gas supply shock.

$Q_{2}<Q_{\text {o }}^{i} \quad$ The quantity of gas injected into the system is below the nominated quantity because of an unexpected decrease in the supply of gas. Consumers are unable to change consumption in real time, so the quantity of gas withdrawn from the system is equal to the nominated quantity $\left(Q^{w_{2}=Q_{\mathrm{o}}}\right)$.

$Q_{2}{ }_{2}-Q^{w} \quad$ The difference between the quantities of injected and withdrawn gas is equal to the size of the system imbalance, which is negative because 
$Q_{2}^{i}<Q^{w}{ }_{2}$. BGT must buy the missing gas in the flexibility market to restore system balance. BGT accepts flexibility bids $1-3$.

$\mathrm{SMP}_{\text {buy }} \quad$ The system marginal price of gas bought by BGT from winning bidders. It is equal to the price of the last accepted flexibility bid.

Data for July 1996 support the relation between ilexibility and spot market prices predicted above, although the period is short (table 4). During 10 days of that month BGT sold gas at a system marginal price below the prevailing spot market price and bought gas at a system marginal price above the spot market price. The system average price was close to the system marginal price on all but one day of trade, reflecting the small spread of prices in flexibility bids. The exception was July 28 , when the system average price exceeded the spot market price even though the system was selling. This exception was caused by the high price of $£ 3.11$ per therm for 170,847 therms sold to National Power, compared with the prevailing system marginal price for system sell of 10.07 pence per therm. According to British Spot Gas Markets (July 29, 1996), the trader for National Power who placed this expensive bid had confused therms with kilowatt-hours.

Table 4 Trading and Prices in the Flexibility Market, July 19-28, 1996

(1 pence per them, unless otherwise indicated)

\begin{tabular}{|c|c|c|c|c|c|c|}
\hline Day & $\begin{array}{c}\text { Volume }^{\mathrm{a}} \\
\text { (millions of therms) }\end{array}$ & SAP & SMP buy & SMP sell & $\begin{array}{l}\text { SAP } \\
30 \text {-day }\end{array}$ & $\begin{array}{c}\text { Spot market } \\
\text { price }\end{array}$ \\
\hline 19 & -2.56 & 15.04 & 15.05 & 8.90 & 12.45 & 12.1275 \\
\hline 20 & 2.81 & 11.72 & 34.87 & 11.71 & 12.56 & 12.1275 \\
\hline 21 & 0 & 12.49 & 35.58 & 8.99 & 12.49 & 12.1275 \\
\hline 22 & 2.00 & 10.88 & 35.31 & 10.24 & 12.51 & 12.1275 \\
\hline 23 & 0 & 12.47 & 35.03 & 9.04 & 12.47 & 12.1275 \\
\hline 24 & 0 & 12.49 & 34.74 & 9.04 & 12.49 & 12.1275 \\
\hline 25 & 0 & 12.58 & 34.44 & 9.01 & 12.58 & 12.1275 \\
\hline 26 & 0 & 12.59 & 34.12 & 9.02 & 12.59 & 12.1275 \\
\hline 27 & 3.79 & 10.72 & 33.78 & 10.54 & 12.61 & 12.1275 \\
\hline 28 & 2.67 & 32.28 & 33.44 & 10.07 & 12.56 & 12.1275 \\
\hline
\end{tabular}

Note: SAP is system average price; SMP is system marginal price. Numbers in bold are the system average or marginal price of accepted flexibility bids, and numbers in italics the system average or marginal price of nonaccepted bids.

Note: The spot market price is approximated by the Heren Index, as calculated by $\mathrm{PH}$ Energy Analysis for July 1996 for the Bacton terminal.

a. A positive number indicates a system sell, a negative number a system buy.

Source: The Heren Index, July 1996 


\section{Financial gas market}

The financial gas market in the U.K. came to existence relatively recently, but it has already experienced major developments. Initially, financial gas instruments were traded mostly by financial and trading institutions, which offered customized financial gas contracts to large customers, shippers or suppliers. The financial gas market was relatively unorganized and small, as only few instruments were traded ${ }^{10}$. An increase in the volumes of natural gas traded in the spot market and corresponding volatility of spot prices have initiated demand for more financial instruments designed to hedge price risks.

The International Petroleum Exchange in London carried out the task of developing standardized financial gas contracts. Originally, the IPE intended to develop both physical and financial gas contracts for delivery to the Bacton terminal, but because of the increasing use and great potential of the on-system market, the delivery point has been changed to the National Balance Point. After complicated negotiations with BGT and OFGAS over an access to BGT's electronic network ${ }^{11}$, the IPE finally introduced its Natural Gas NBP contract on January 31, 1997, as the first gas futures contract in Europe. This marked a start of trading of standardized financial gas contracts in the U.K.

A single IPE Natural Gas NBP contract is for delivery of 1,000 therms of natural gas per day at the $\mathrm{NBP}^{12}$. Trading takes place in multiples of 5,000 therms per day through the IPE automated Energy Trading System or in the over-the-counter market. Contracts can be traded in groups of individual days on a monthly basis up to 12 months into the future. The IPE has also introduced a Balance of the Month contract which for delivery in all days remaining in the current month. If delivery is to occur, traders are required to follow BGT's nominations process and coordinate with the London Clearing House to fulfill their obligations.

The IPE natural gas futures contract has become increasingly popular among gas traders in the U.K. It was widely accepted by the gas industry because of its central delivery location and smooth administration. For example, total volume of traded gas on July 31 , 1997, was almost 30 million therms, representing about $40 \%$ of total U.K. daily production of natural gas (IPE 1997b). The IPE also facilitates trading of the Exchange of Futures for Physicals, a popular contract that allows traders to liquidate equal and opposite physical and financial positions in natural gas, and intends to introduce a natural gas options contract. Although some say that the sole U.K. natural gas market may not be large enough to allow efficient trading of natural gas futures contracts, the success of the

\footnotetext{
${ }^{10}$ There have been only 10 to 15 swap transactions so far, according to Colin Bryce of Morgan Stanley International in London.

"For more details on IPE's activities in preparation of natural gas physical and financial contracts, see European Natural Gas Daily, September 23, 1996, published by Petroleum Argus Ltd., London..

${ }^{12}$ This paragraph draws on (IPE 1997a).
} 
IPE Natural Gas NBP contract has disproved these predictions. The IPE eyes gas markets in continental Europe, which may provide a number of opportunities for financial gas trading once they are liberalized.

\section{Capacity Markets}

Capacity markets enable industry participants to purchase the pipeline capacity and transportation services needed to transport gas from the point of purchase to the point of consumption. A primary capacity market is supplied by the pipeline operators, which sell their capacity and transportation services to shippers. Revenues from the primary capacity market should recover the operator's costs of constructing the pipeline and transporting the gas. Therefore, the price for capacity (the capacity charge) should generate enough revenues to recover the fixed costs, and the price for transportation services (the commodity charge) the variable costs, of the pipeline operator.

A secondary capacity market increases the efficiency of the pipeline system. Shippers with temporarily spare capacity can resell it to market participants lacking capacity. If demand for capacity can be met by existing capacity offered in the primary and secondary markets, the pipeline operator need not install new pipelines. Selling shippers use the revenues from resold capacity to offset the costs of capacity purchased in the primary market. Buying shippers can decide whether to purchase capacity in the primary or secondary market, depending on the prices. An efficient price for capacity in the secondary market should reflect the opportunity costs of capacity, which vary according to the degree of congestion in the pipeline system.

Capacity markets in the U.K. are framed along BGT's pipeline and storage network. Shippers must purchase pipeline capacity either from BGT in the primary market (capacity booking) or from shippers with spare capacity in the secondary market (capacity trading). Capacity booking is typically performed by signing a 12 -month firm transportation contract with BGT. Capacity trading is done through the auctioning of spare capacity or bilateral trading between two shippers (figure 7). 


\section{Figure 7 Pipeline Capacity Booking and Trading}

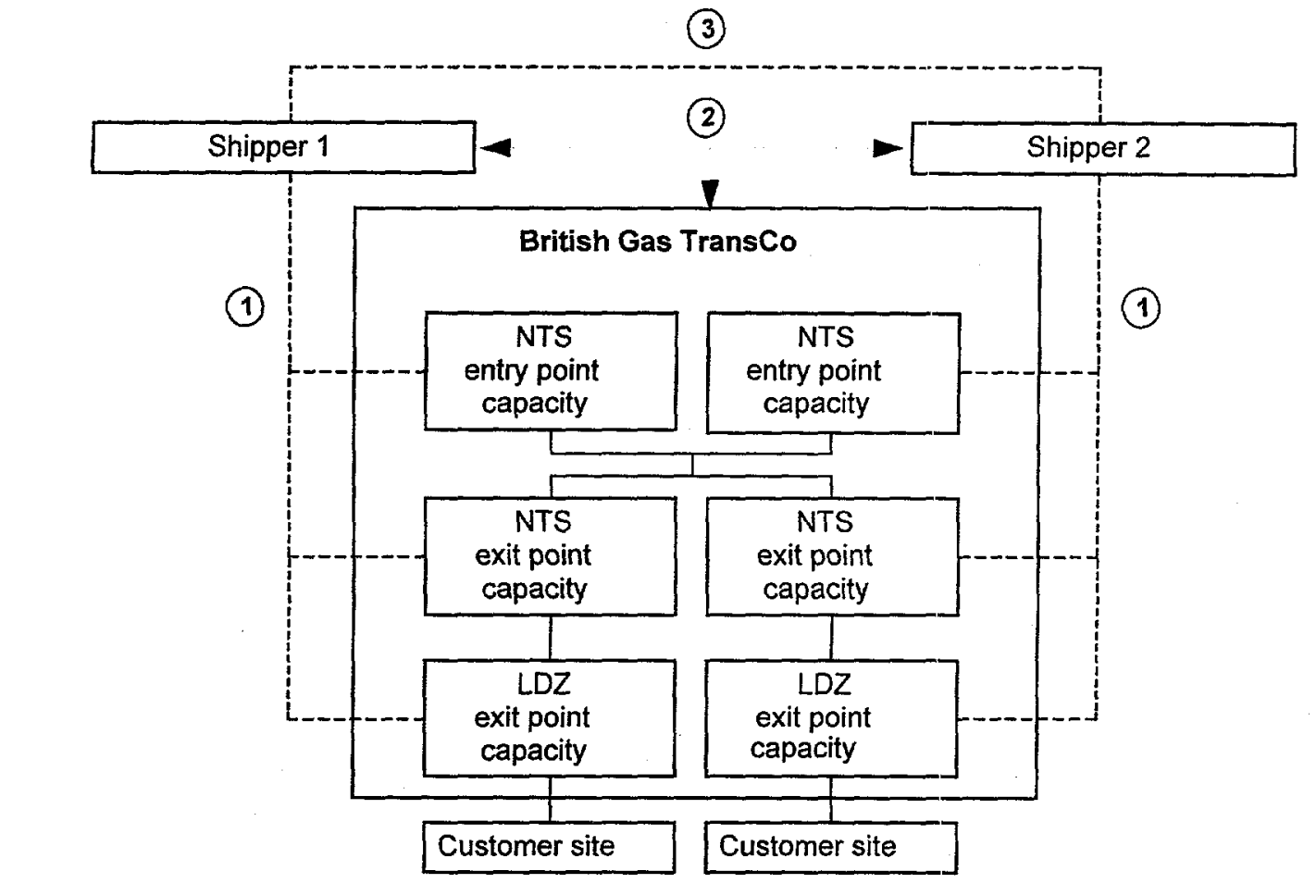

(1) Shippers book capacity from British Gas TransCo on all three levels (typically a 12-month contract).

(2) Shippers trade free capacity and notify British Gas TransCo of the new capacity owner.

(3) Shippers settle the trade financially.

Note: NTS is national transmission system; LDZ is local distribution zone.

Source: Author's compilation

\section{Primary capacity market}

In the U.K. primary capacity market shippers typically book capacity under a 12-month contract with BGT at three locations:

- At an entry point to the national transmission system (NTS) - NTS entry capacity.

- At an exit point from the national transmission system - NTS exit capacity.

- At an exit point from the local distribution zone (LDZ) - LDZ capacity.

In addition, shippers can book storage capacity, consisting of storage space and deliverability (a rate of gas withdrawal from storage). 
BGT provides transportation services for shippers under contracts for either firm or interruptible transportation. Firm customers must pay all relevant capacity charges as well as a commodity charge. Interruptible customers pay an NTS entry capacity charge and a commodity charge. Interruptible transportation is available only for transportation of more than 200,000 therms a year, and it can be interrupted for up to 45 days each year. In addition, BGT offers nominated interruptible transportation that can be interrupted for more than 45 days a year. Customers using this service pay an NTS entry capacity charge as well as discounted NTS and LDZ commodity charges.

Because BGT has a monopoly position in gas transportation in the U.K., its rates for capacity and transportation services are regulated by Ofgas, under a mix of rate-of-return and price cap regulatory methods. Rates are first calculated to ensure that BGT's revenues from transportation cover its total costs and provide a return on capital. They are then subject to a price cap, which limits growth in revenues and allows for productivity improvements over a certain period. When the price cap expires, Ofgas reviews BGT's revenues, costs, and asset value and, based on its findings, sets a new price cap with necessary adjustments. The rate structure is determined by BGT, although Ofgas closely monitors the structure and approves any changes. Ofgas's aim is to support long-run efficiency in the primary capacity market and transportation. The underlying objectives are therefore to protect consumers from BGT's market power and allow BGT's shareholders to earn a fair rate of return.

BGT's rate structure for transportation and capacity is gradually being revised to better reflect the true costs of these services. ${ }^{13}$ The current rate structure, which came into effect in October 1994, introduced locational pricing for capacity and a 50/50 split of revenues between capacity and commodity charges. It was preceded by a rate structure built around distance-based transportation charges and the same 50/50 split between capacity and commodity charges. The goal of BGT and Ofgas is to provide market participants with the right signals about the efficient location of sites and the size of consumption. Despite substantial improvement in the efficiency of rates, Ofgas is pushing BGT to reduce commodity charges in order to achieve a 90/10 split between capacity and commodity charges. This rate structure should better reflect the ratio between BGT's fixed and variable costs.

The pricing of NTS capacity is based on the long-run marginal cost of capacity. Capacity charges are determined for each NTS entry point and about 80 NTS exit points, which are structured into 34 zones. A charge for each point is determined by an approximation of a matrix of the long-run marginal costs of the capacity needed to meet the incremental demand for transportation from a particular point to all exit zones. BGT, in cooperation with Ofgas, has decided to use long-run marginal cost pricing of capacity rather than short-run marginal cost pricing, which would lead to high price volatility. Although longrun marginal cost pricing does not achieve the same allocative efficiency as short-run

\footnotetext{
${ }^{13}$ This section is based on Higson 1996.
} 
marginal cost pricing does, it should give market participants more certainty in their investment decisions. In addition, an active secondary market with short-term capacity should facilitate efficient allocation of capacity in the short term, so that the allocative inefficiencies of long-run marginal cost pricing should be limited.

NTS capacity charges, based on the long-run marginal cost of capacity, recover only 55 percent of fixed costs, or 50 percent of the total costs of transportation. BGT has decided to recover the rest through NTS commodity charges, despite Ofgas's opposition. As a result. NTS commodity charges have been derived from the remaining 50 percent of BGT's total costs of running the national transmission system, rather than from the variable costs of transportation, which represent about 10 percent of the total costs. The adopted principle of a 50/50 split between capacity and commodity charges has suppressed the consumption of transportation services, especially of interruptible transportation, because users face inefficiently high costs in transporting their gas through the system. In addition, the NTS commodity charge is "postalized" - set at the same level for the entire national transmission system - ignoring any differences in transportation costs among regions.

LDZ capacity and commodity charges are based on the principle that the size of a user's peak daily capacity determines the fixed and variable costs that the user imposes on the pipeline system. Shippers with low peak daily capacity pay higher rates than shippers with high peak daily capacity. The rationale for this is that a shipper with higher peak daily capacity uses a higher-pressure tier of the pipeline system and higher volumes of gas, resulting in lower per-unit costs for capacity and transportation. Both LDZ capacity and commodity charges are postalized for all LDZs. This creates inefficiency, because users do not face the true costs of capacity and transportation.

BGT and Ofgas continue to enhance the rate structure. One of the most important tasks for BGT with regard to the gradual opening of the tariff market is to establish a separate rate structure for transportation to tariff market customers. Other tasks include changing the split between capacity and commodity charges from 50/50 to $90 / 10$ and deriving zone-specific LDZ capacity and commodity charges.

\section{Secondary capacity market}

Any combination of NTS entry and exit point capacity or LDZ exit point capacity that is held by a shipper is eligible for resale in the secondary capacity market except for LDZ exit capacity at a non-daily metered site. The secondary capacity market experiences little activity, however, because of its short existence and the abundance of capacity in the primary market.

There are two mechanisms for capacity trading in the secondary market: bilateral trading and auction (both mechanisms are also used in the capacity release program in the U.S. natural gas industry). Bilateral capacity trading takes place when two shippers directly agree on the conditions of trade. After the deal is concluded, the selling shipper records 
its offer for sale of capacity along with the name of the buying shipper on the electronic network. The buying shipper approves this transaction by confirming the trade. The selling shipper must notify BGT of the capacity trade to make a change in allocation. It also remains responsible for payment of capacity charges to BGT.

The auctioning of capacity, which takes place through the electronic network, has five stages (figure 8 ). ${ }^{14}$

- A shipper with spare capacity posts a capacity offer specifying the quantity, location, duration, and suggested price of capacity.

- Shippers seeking capacity can view available bids in the network and post their bids for part or all of the offered capacity. They can also view the bids already posted, but not the names of shippers. Once a bid is posted, it cannot be amended, but it can be withdrawn. Shippers can post more than one bid against an offer.

- The selling shipper reviews the posted bids and selects one of them.

- The selling shipper notifies BGT of the new owner of the capacity. Payment of the capacity charge remains the responsibility of the selling shipper.

- The selling and buying shippers settle the trade financially. BGT does not participate in the financial settlement.

${ }^{14}$ This description of capacity auctioning is based on BGT 1996. 


\section{Figure 8 Capacity Resale}

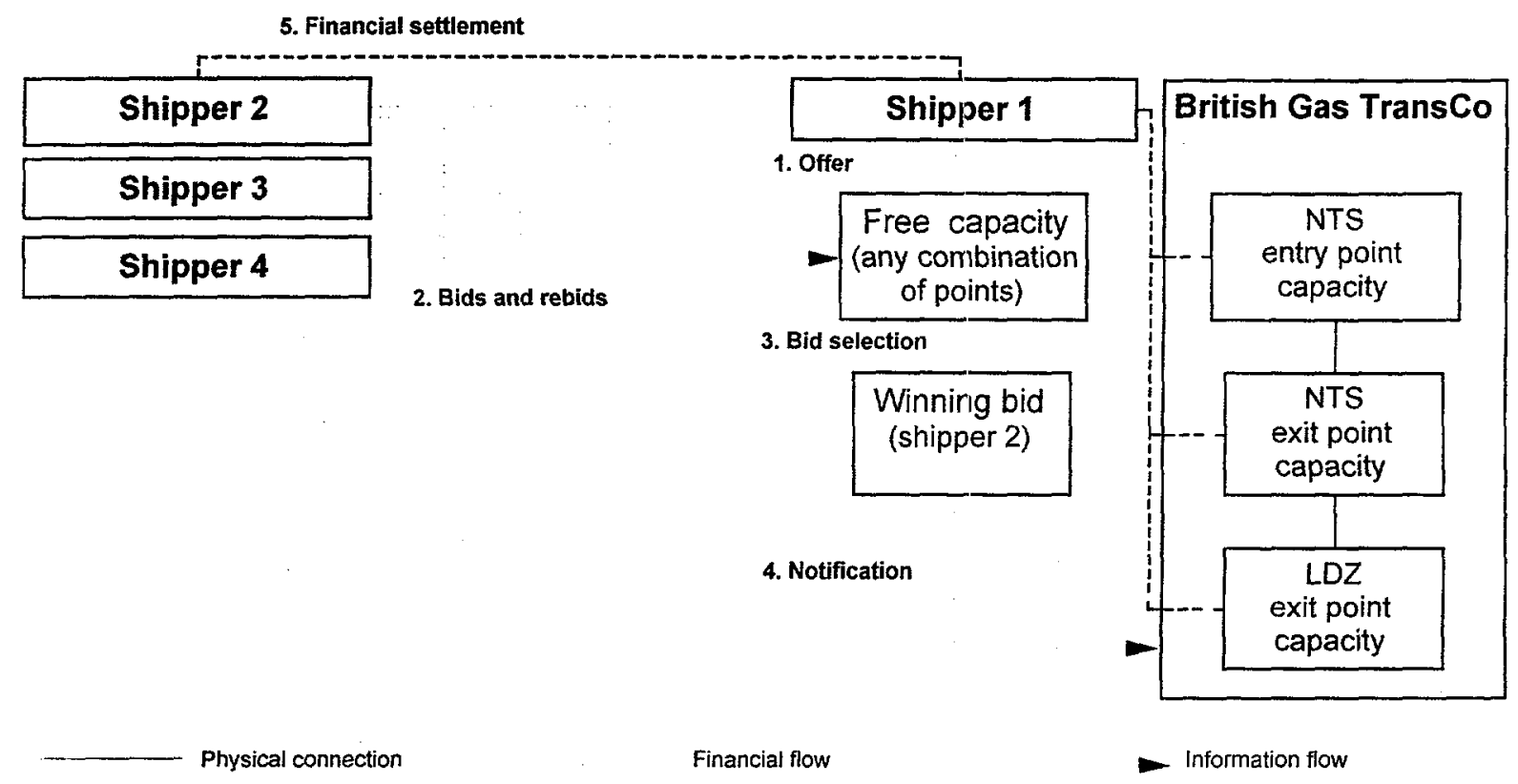

Source: Author's compilation

The price of capacity in an efficient secondary market reflects the SRMC and the opportunity costs of capacity. It is high during peak periods when the pipeline system is congested and the opportunity costs of capacity are high. On the other hand, the price of capacity is low during off-peak periods when the system has plenty of unused capacity and the opportunity costs of capacity are equal or close to zero.

Under the existing institutional arrangements, the secondary capacity trading in the U.K. is being developed mainly along the natural gas trading in the "on-system" market. Increasing liquidity of the "on system" gas market and uniformity of electronic systems make gas and capacity transactions at the NBP a viable option for shippers to match their gas and capacity needs on daily, monthly or even longer-term bases. As a result shippers increasingly trade secondary pipeline capacity, particularly in the short-term, although it may often be "bundled" with natural gas traded at the NBP. 


\section{Conclusion}

The U.K. experience in natural gas markets shows that the transition from a monopolized to a competitive natural gas industry must be accompanied by the creation of an appropriate regulatory and institutional framework that shields entrants from the exercise of market power by the incumbent and gives participants in the gas market equal rights in dealing with the transmission monopolist.

A key part of this framework in the U.K. natural gas industry is the Network Code, a mechanism for optimizing gas transportation and system balancing in the decentralized gas industry. The code is a set of rules that determine how the pipeline system users cooperate with the system operator when seeking transportation services. They also determine how the system will be operated and the system balance maintained. The operator uses price signals generated through the flexibility mechanism to choose the balancing measures with the lowest cost to society.

Physical natural gas is traded under four mechanisms. Long- and medium-term gas contracts are traded in a bilateral contract market. Short-term gas is traded in spot markets that have been developed at the entry points to the pipeline network. The other two mechanisms, used for gas trading in the pipeline network, imitate a systemwide spot market. The flexibility mechanism facilitates the trading of short-term and very shortterm (swing) gas through an auction, and the on-system market provides an opportunity to trade medium- and short-term gas and imbalances.

Pipeline capacity and transportation services are sold in a primary market at preannounced rates that are regulated because of the natural monopoly characteristics of gas transportation in the pipeline network. A secondary market facilitates capacity trading by auction or through bilateral dealing at deregulated rates.

By contrast to the physical gas market, the financial gas market in the United Kingdom is underdeveloped. Only limited price risk hedging is provided by financial intermediaries, on a case-by-case basis. Other financial instruments, such as futures or options contracts, are unavailable but are being developed. The underdevelopment of the financial gas contract market is attributable to the brief existence of the short-term physical gas market. Increasing use of spot markets can be expected to increase the demand for risk hedging instruments.

The most important issue today is whether industry participants can reach a consensus on how to enhance the existing framework to improve the efficiency of markets. Development of the financial gas market will require cooperation between BGT and Ofgas to provide the International Petroleum Exchange access to BGT's electronic network so that it can record and settle transactions. And both BGT and its customers will need to contribute time and resources to developing an efficient tariff structure for pipeline capacity and transportation services in the contract and tariff markets. 
The deintegrated natural gas industry in the United Kingdom is off to a promising start. These above features of the industry, along with continued unbundling and restructuring of transportation charges, should support the development of competition in gas and capacity markets and promote efficient functioning of the industry after full liberalization of retail supply in 1998 . 


\section{Appendix}

\section{Structure and Regulation of the U.K. Natural Gas Industry}

The natural gas industry in the U.K. has undergone dramatic changes in structure and regulation. During the past 10 years deregulation has introduced competition in natural gas supply to large and medium-size users, facilitated the development of independent gas trading and supply companies, and gradually changed the operation of the pipeline system. (See figure A.1 for the structure of the U.K. natural gas industry.)

The deregulation has benefited end users through declining real prices for natural gas. According to data from the Department of Trade and Industry, between 1986 and 1995 residential prices fell by 24 percent in real terms, industrial prices by 47 percent, and prices for electricity producers by 54 percent. The price declines were accompanied by a 38 percent increase in natural gas consumption between 1986 and 1995. The growth in consumption was particularly strong among electricity producers, whose consumption increased by 2,100 percent, and commercial users, whose consumption rose by 104 percent. (For an overview of natural gas prices and consumption, see tables A.1-A.3 and figures A.2-A.4.)

The natural gas industry in the U.K. has been transformed from a vertically integrated to a deintegrated industry. Before 1986 British Gas (BG) operated as a publicly owned, monopolistic transporter and supplier of natural gas. Only production was open to competition, and it was dominated by multinational oil companies. In 1986 the government privatized British Gas and partially deregulated gas supply. British Gas retained its monopoly in supply to low-volume customers in the tariff market, but lost its exclusivity in supply to high-volume customers in the contract market, where it competes with about 40 independent suppliers.

About 40 companies are engaged in natural gas production and exploration. The major production areas are in the North and Irish Seas, which produced 46 billion cubic meters of gas in 1993, about 85 percent of domestic consumption. The remaining 15 percent $(7.5$ billion cubic meters) was imported from Norway and Algeria. The share of imports in natural gas supply has gradually decreased, from 22 percent in 1986 to 2 percent in 1995 . (For an overview of natural gas production and imports, see table A.4 and figure A.5.)

Suppliers' means of acquisition of natural gas has shifted from bilateral long-term contracts to medium- and short-term contracts and a spot market. Before 1989 British Gas traditionally bought 100 percent of gas production under long-term contracts. Many of those contracts were (and still are) "depletion" contracts. In an attempt to promote a policy of open access to the British Gas pipeline network, Ofgas introduced the 90:10 rule in 1989, which prohibited British Gas from contracting for more than 90 percent of deliveries from any field on the U.K. continental shelf. The remaining 10 percent of gas production became available to British Gas's competitors - independent shippers and suppliers. This rule forced producers to market their gas to buyers, and several producers 
set up marketing affiliates. Producer prices of gas, or beach prices, were subject to negotiation between producers and either British Gas or independent shippers and suppliers.

Initially, British Gas operated both natural gas supply and transportation as a merchant pipeline. In 1993 Ofgas asked British Gas to build "Chinese walls" (separating accounting) between the transportation and supply arms. This led to the unbundling of British Gas into British Gas Energy (BGE) and British Gas TransCo (BGT).

BGT operates transportation and distribution pipelines and storage. The pipeline network is composed of the following segments:

- The national transmission system - 5,900 kilometers of high-pressure pipelines.

- Regional transmission systems - about 12,500 kilometers of medium-pressure pipelines.

- Local distribution networks - about 232,000 kilometers of low-pressure pipelines.

- Storage - seven storage facilities linked to the national transmission system.

The national transmission system contains six entry points, or terminals, where producers can deliver their gas. In addition, gas can enter the system from BGT's storage facilities. Gas leaves the system through about 80 exit points, organized into 34 exit zones. These zones coincide geographically with the 34 local distribution zones, which contain pipelines for the regional transmission systems and local distribution networks. Rates and conditions for access to BGT's pipeline network are regulated by Ofgas under a mix of rate-of-return and price cap regulation. Rates for carriage must recover BGT's proportionate costs and return on capital, and they are subject to a price cap. BGT is a monopolistic provider of transportation services and pipeline capacity in the U.K., although other companies can construct and operate pipelines. 
Figure A.1 Structure of the U.K. Natural Gas Industry

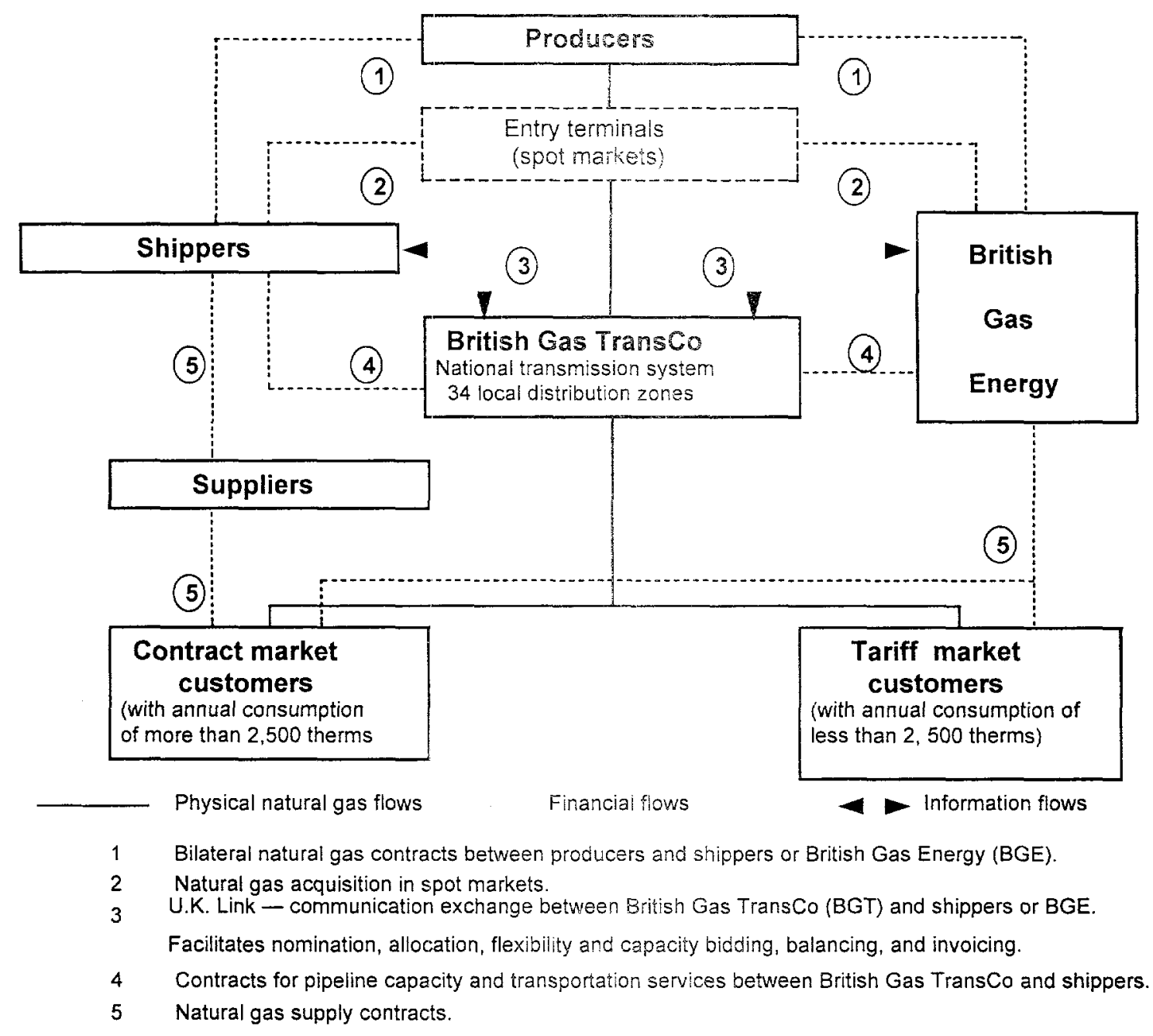

The natural gas market is divided into contract and tariff markets. The contract market is composed of consumers using more than 2,500 therms a year. It is open to competition, and BGE competes directly with about 40 independent suppliers. The market share of British Gas fell from almost 100 percent in 1988 to about 80 percent in 1992. Prices are subject to negotiation between consumers and BGE or independent shippers and suppliers. BGE is required to publish its rates for both firm and interruptible gas. Published rates must disclose a charge for transportation and an energy component, including conditions of transportation.

The tariff market is composed of consumers using less than 2,500 therms a year. At present, there is no competition in the tariff market, although a pilot program of retail competition involving 500,000 consumers was launched in April 1996 in southeastern England. There, BGE competes with nine other suppliers. In the first month of the program about 6 percent of consumers switched from BGE to another supplier, and it is 
expected that BGE will lose about 12.5 to 25 percent of the southeastern market (Ernst \& Young Energy Services Group 1996). In April 1997 another 1.5 million retail customers were allowed to choose a supplier, and at the beginning of 1998 full retail competition will be introduced. BGE is expected to lose about 25 percent of the entire tariff market (Royle 1996).

The regulator of the gas industry is the Office of Gas Supply (Ofgas), which regulates tariffs and the industry structure. Other institutions with regulatory authority over the industry include the Office of Fair Trading and the Monopolies and Mergers Commission, together the competition watchdogs, and the Department of Trade and Industry, the sectoral ministry.

Tariffs for tariff market customers are regulated by Ofgas on the basis of the following price cap formula:

RPI $-X+$ GPI $-Z+E+K$, where

$\mathrm{RPI}$ is the retail price index.

$X$ is the productivity improvement factor, currently set at 5 .

GPI is the gas price index, constructed by Ofgas to reflect British Gas's average cost of gas.

$Z$ is the efficiency factor of GPI, currently set at 1.

$E$ is the energy efficiency expenditure factor.

$K$ is a correction factor that allows over- or underrecovery of costs in any particular year to be corrected in later years.

Tariffs cannot be changed more than twice a year without the approval of Ofgas.

Tariffs for transportation and storage are also regulated by Ofgas. Tariffs are first calculated to generate revenues that cover BGT's total costs and return on assets. Then tariffs are subject to the following price cap formula:

$M_{i}=\left[1+\left(\mathrm{RPI}_{t}-X\right) / 100\right] P_{t-1}-K$, where

$M_{l}$ is the maximum revenue per therm transported by BGT.

RPI is the retail price index.

$X$ is the productivity improvement factor, currently set at 5 .

$P_{t-1}$ is the maximum revenue per therm that BGT was allowed to earn in the previous year.

$K$ is a correction factor that allows over- or underrecovery of costs in any particular year to be corrected in later years.

This formula came into effect on October 1, 1994, when BGT introduced a new structure for transportation and storage charges. 
BGT and Ofgas are presently engaged in talks about further restructuring of transportation and storage charges to promote the efficient use of and investment in the pipeline system and to unbundle and open to competition other lines of business, such as service connection, emergency services, and meter installation and reading. Ultimately, BGT should operate solely as a transporter of natural gas and a provider of system balance and reliability in the deintegrated, unbundled natural gas industry. 
Table A.1

U.K. Gas Prices Index, 1990=100

Current Prices (excl. VAT)

$\begin{array}{lcccc}\text { Year } & \text { Beach } & \text { Residential } & \text { Industrial } & \text { El. Producers } \\ 1986 & & 89.93 & 113.43 & 137.74 \\ 1987 & & 89.05 & 106.78 & 110.53 \\ 1988 & 94.91 & 89.75 & 101.69 & 91.73 \\ 1989 & 99.02 & 93.64 & 98.31 & 100.00 \\ 1990 & 100.00 & 100.00 & 100.00 & \\ 1991 & 108.61 & 106.89 & 100.91 & \\ 1992 & 107.05 & 106.71 & 104.43 & \\ 1993 & 102.15 & 102.60 & 102.74 & 106.17 \\ 1994 & 110.18 & 102.60 & 103.65 & 100.30 \\ 1995 & 109.59 & 104.13 & 90.35 & 96.69\end{array}$

Note: Gas Prices Index for Power Producers 1989=100

Source: DTI

Table A.2

U.K. Gas Prices Index, 1990 $=100$

Real Prices (excl. VAT)

$\begin{array}{lcccc}\text { Year } & \text { Beach } & \text { Residential } & \text { Industrial } & \text { El. Producers } \\ 1986 & & 114.12 & 143.94 & 164.36 \\ 1987 & & 107.55 & 129.07 & 125.60 \\ 1988 & 108.02 & 102.22 & 115.78 & 98.30 \\ 1989 & 105.28 & 99.62 & 10.56 & 100.00 \\ 1990 & 100.00 & 100.00 & 100.00 & \\ 1991 & 101.96 & 100.37 & 94.78 & \\ 1992 & 96.09 & 95.79 & 93.74 & \\ 1993 & 88.85 & 89.22 & 89.31 & 86.85 \\ 1994 & 93.93 & 87.54 & 88.40 & 80.48 \\ 1995 & 91.39 & 86.85 & 75.36 & 75.81\end{array}$

Note: Gas Prices Index for Power Producers $1989=100$

Source: DTI 
Table A.3

Natural Gas Consumption in the U.K., 1986-1995

(GWh)

$\begin{array}{lcccccc}\text { Year } & \text { Residential } & \text { Commercial } & \text { Industrial } & \text { El. Producers } & \text { Other* } & \text { TOTAL } \\ 1986 & 299,929 & 84,348 & 151,269 & 6,200 & 46,535 & 588,281 \\ 1987 & 307,578 & 86,664 & 164,442 & 6,200 & 49,041 & 613,925 \\ 1988 & 300,515 & 137,420 & 150,235 & 6,200 & 1,345 & 595,715 \\ 1989 & 290,557 & 134,403 & 160,050 & 6,200 & -9,479 & 581,731 \\ 1990 & 300,410 & 138,446 & 164,993 & 6,400 & -11,817 & 598,432 \\ 1991 & 333,963 & 158,738 & 158,354 & 6,561 & -14,116 & 643,500 \\ 1992 & 330,101 & 150,795 & 147,584 & 17,894 & -3,234 & 643,140 \\ 1993 & 340,162 & 153,975 & 148,707 & 81,778 & -4,798 & 719,824 \\ 1994 & 329,710 & 156,315 & 164,557 & 114,575 & 2,180 & 767,337 \\ 1995 & 326,010 & 171,860 & 165,022 & 145,790 & 3,223 & 811,905\end{array}$

* Includes public administration, agriculture and balancing items

Source: DTI

\section{Table A.4}

Natural Gas Production and Imports in the U.K., 1986-1995 (GWh)

$\begin{array}{lccc}\text { Year } & \text { Production } & \text { Imports } & \text { Total } \\ 1986 & 483040 & 137099 & 620139 \\ 1987 & 508126 & 128893 & 637019 \\ 1988 & 491249 & 115441 & 606690 \\ 1989 & 481257 & 113770 & 595027 \\ 1990 & 531377 & 79833 & 611210 \\ 1991 & 591795 & 72007 & 663802 \\ 1992 & 602322 & 61255 & 663577 \\ 1993 & 707685 & 48525 & 756210 \\ 1994 & 755763 & 33053 & 788816 \\ 1995 & 826722 & 19457 & 846179\end{array}$

Source: DTI 


\section{Figure A.2}

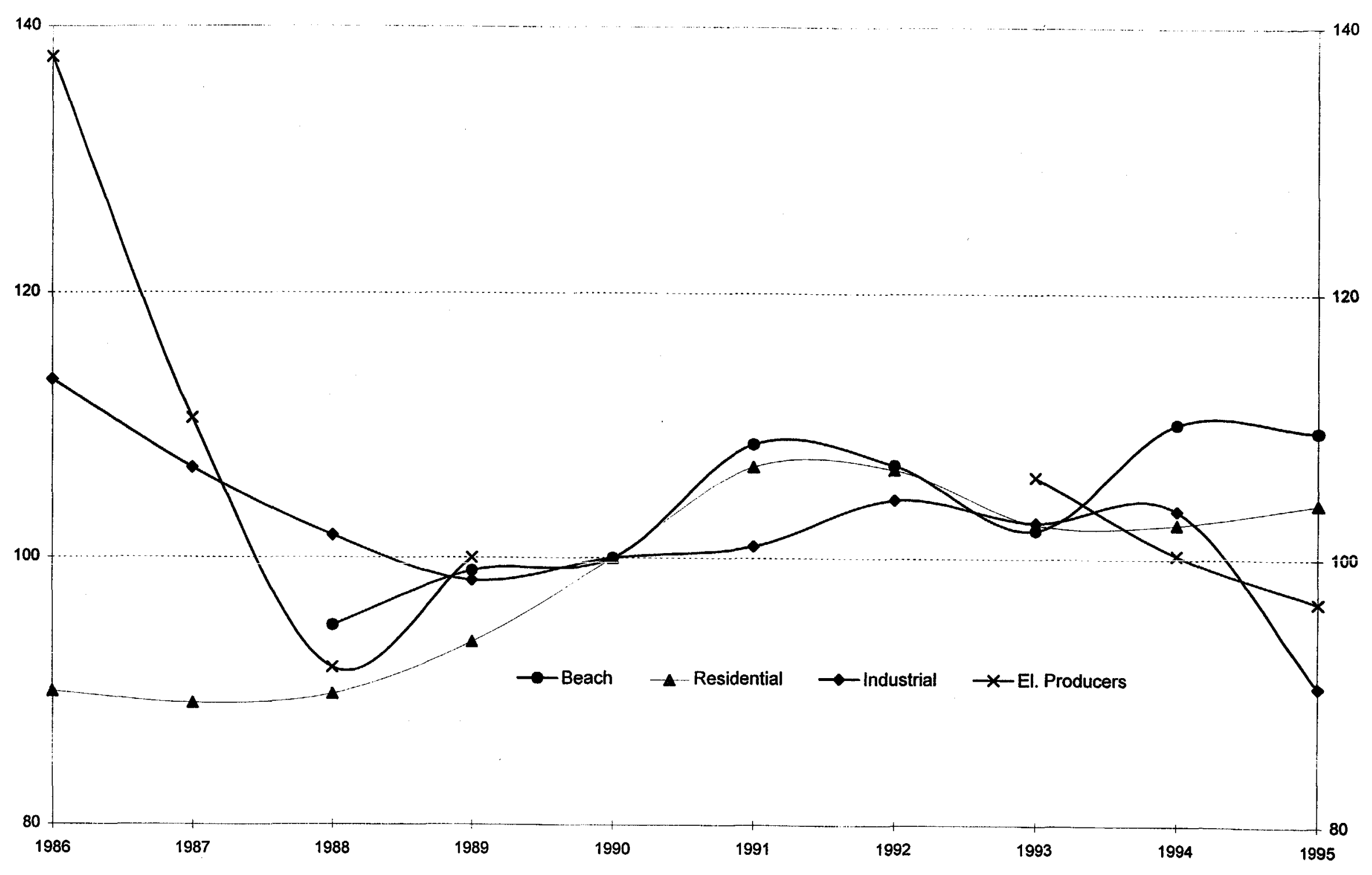




\section{Figure A.3}

175

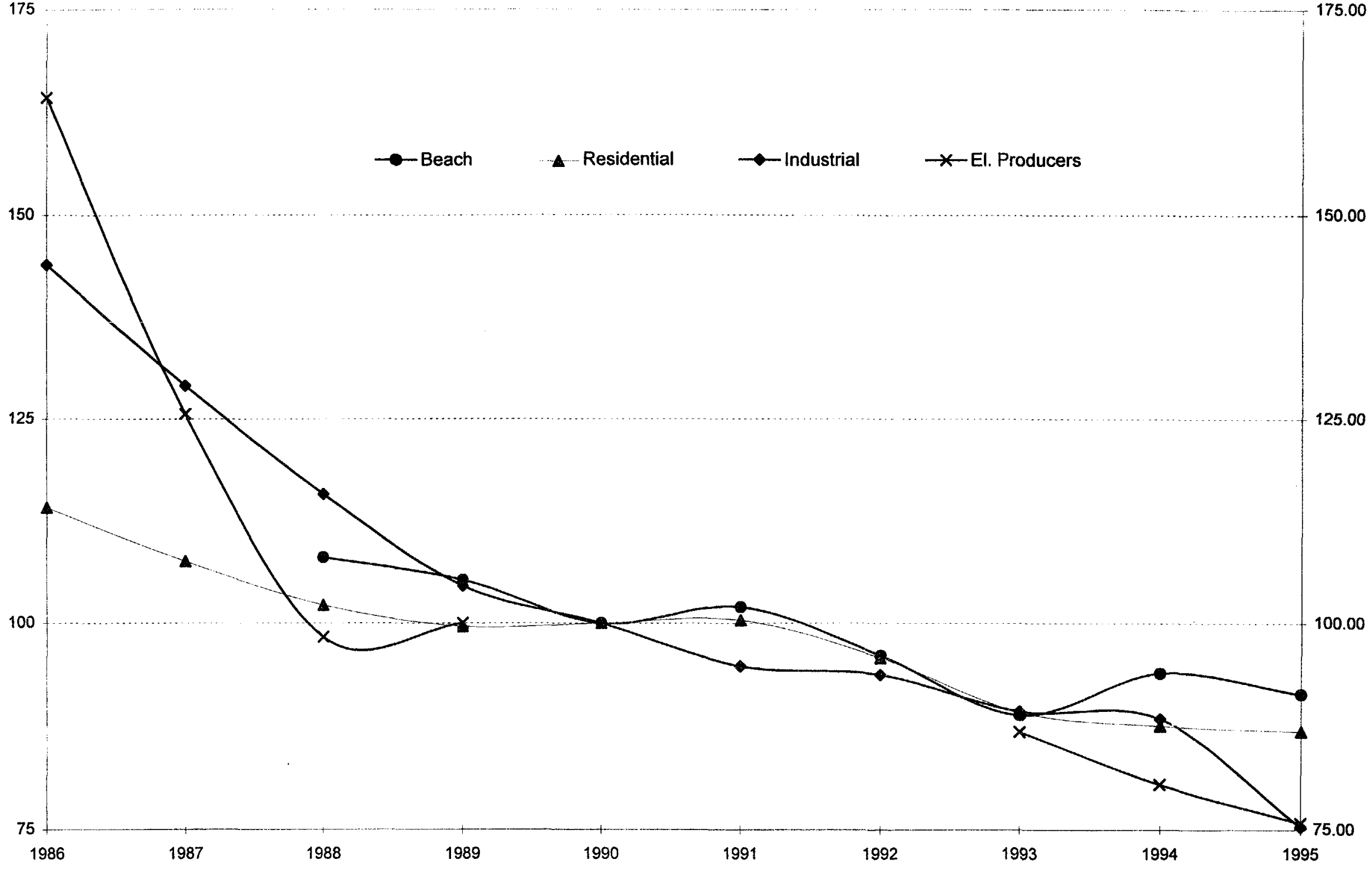

Index of Real Gas Prices, $1990=100$

175.00

0.00

.00

0.00 


\section{Figure A.4}

900,000

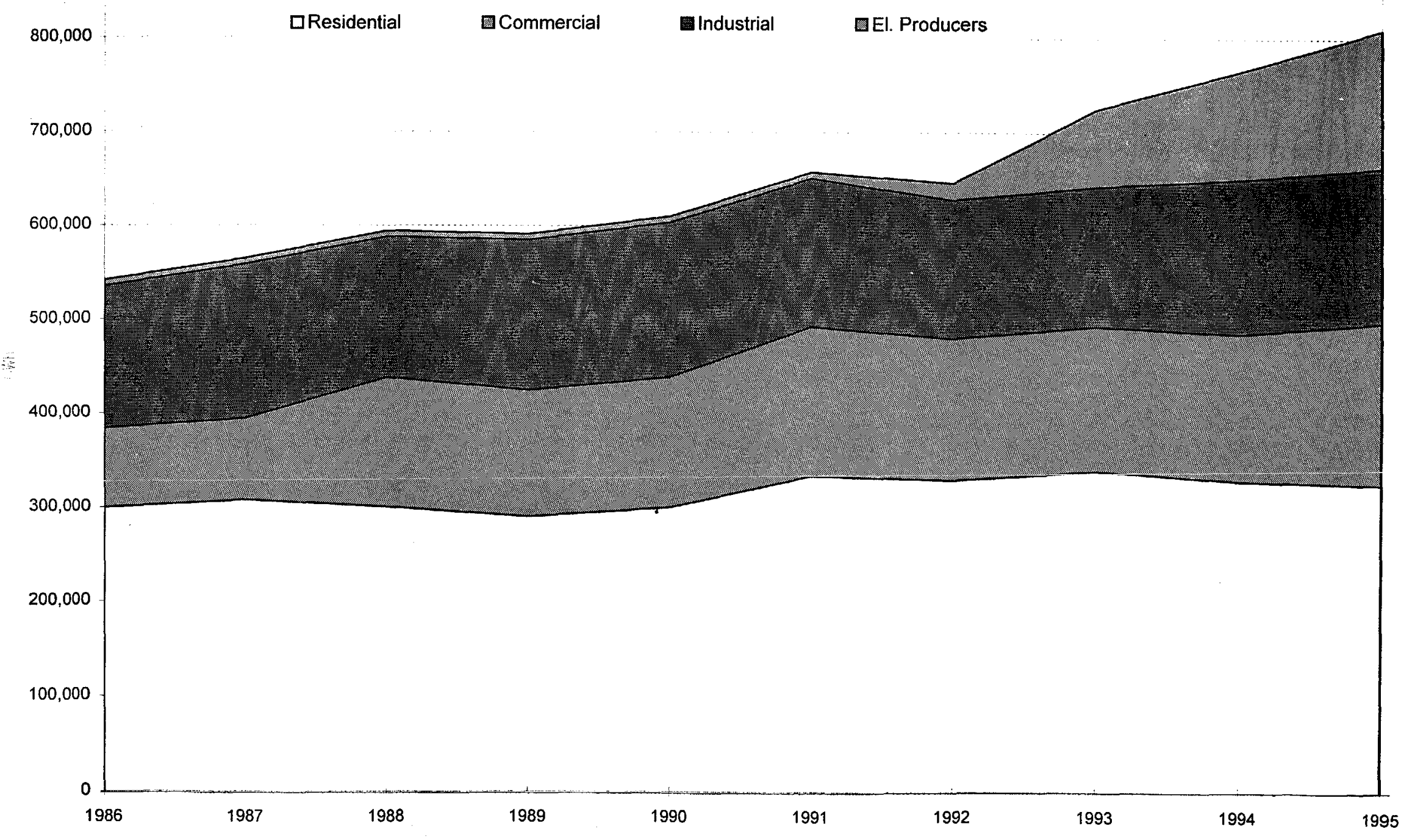


Figure A.5

900,000

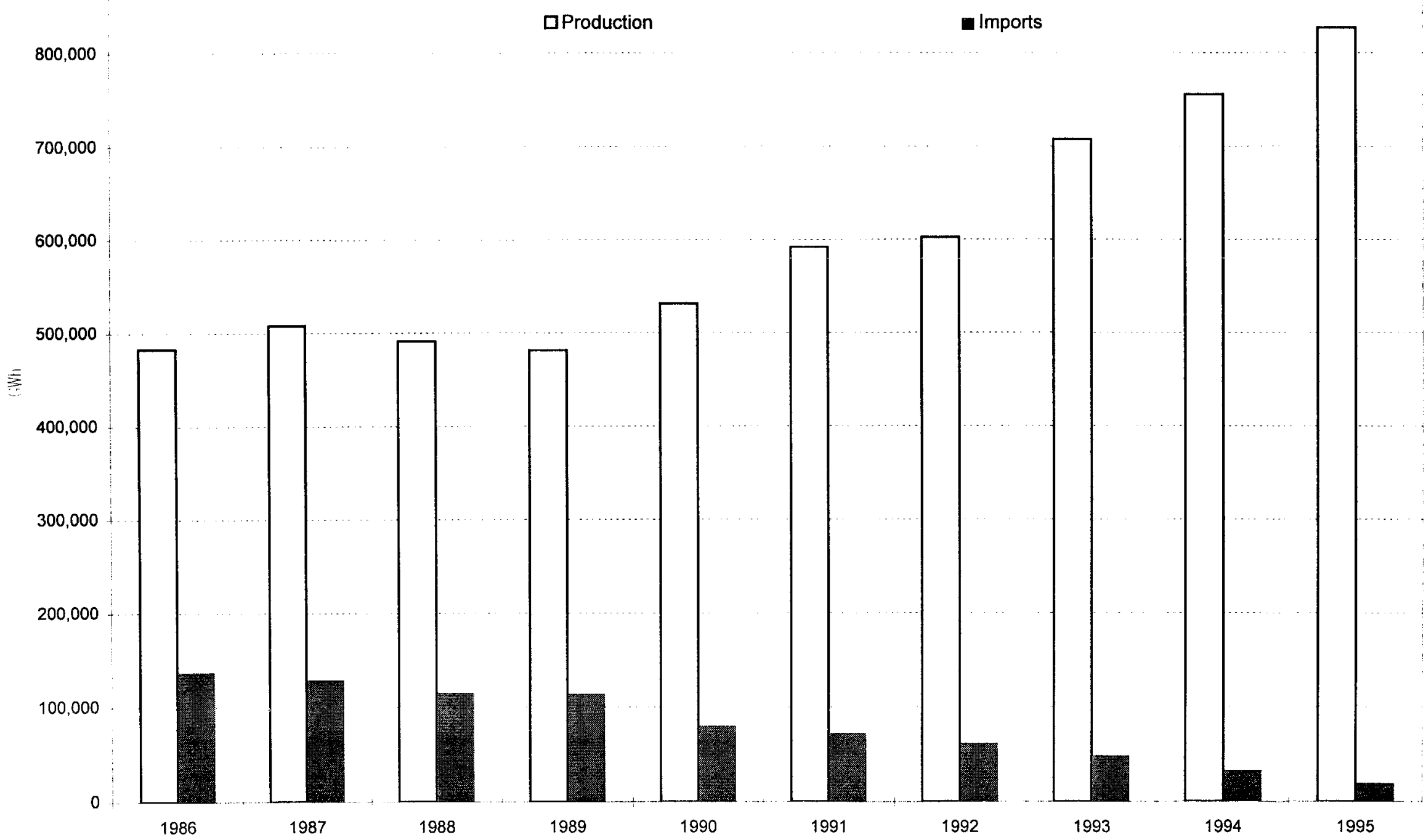




\section{References}

BGT (British Gas Transco). 1996. Gas Transportation Charges 1995/96. London

BGT. 1996. Network Code: The Summary. London.

British Spot Gas Markets. July 26, 1996. PH Energy Analysis, London.

British Spot Gas Markets. July 29, 1996. PH Energy Analysis, London.

Bryce, Colin. 1996. Personal communication. Morgan Stanley, London.

Ernst \& Young Energy Services Group. 1996. Presentation on developments in UK energy utilities at the World Bank, Industry and Energy Department, Washington, DC. June 11.

Gas Matters. Britain's Network Code is Up and Running. March 1996. EconoMatters, London.

Higson, Mark. 1993. "A Pricing Structure for Gas Transportation and Storage." A consultation document. OFGAS, London.

International Energy Agency. 1994. Natural Gas Transportation: Organization and Regulation. OECD/EIA, Paris.

International Petroleum Exchange (IPE). 1997a. Natural Gas (National Balancing Point) Contract: Contract Specification. The IPE Web Page http://www.ipe.uk.com.

IPE. 1997b. Natural Gas Futures Break Through Records. Press Release (July 31). London

National Economic Research Associates (NERA). 1995. Gas Sector Structure \& Regulation in Selected OECD Countries. London.

The Office of Gas Supply (OFGAS). 1994. Proposed Changes to the Gas Tariff Formula. A consultation document. London.

OFGAS \& DTI. 1994. Competition and Choice in the Gas Market. A joint consultation document. OFGAS, London.

Petroleum Argus European Natural Gas Daily, September 23, 1996. Petroleum Argus, London.

Petroleum Argus European Natural Gas Daily, October 3, 1996. Petroleum Argus, London. 
PH Energy Analysis. 1996. The Heren Index: Monthly Gas Market Report and Valuation (July). London.

Powell, William. 1996. Personal communication. Editor of British Spot Gas Markets, PH Energy Analysis, London.

Roeber, Jim. 1996. "The Development of the U.K. Natural Gas Spot Market." Energy Journal Vol 17, No.2, pg. 1-15.

Royle, Gundi. 1996. "British Gas: Light at the End of a Long Tunnel." Investment Research U.K. and Europe. Morgan Stanley International, London. 


\section{Policy Research Working Paper Series}

\section{Title}

Author

Date

WPS1869 Risk Reducation and Public Sjending Shantayanan Devarajan Jeffrey S. Hammer

WPS1870 The Evolution of Poverty and inequality in Indian Villages

WPS1871 Just How Big is Global Production Sharing?

WPS1872 How integration into the Central African Economic and Monetary Community Affects Cameroon's Economy: General Equilibrium Estimates
Raji Jayaraman

Peter Lanjouw

Alexander J. Yeats

Ferdinand Bakoup

David Tarr
WPS1873 Wage Misalignment in CFA Countries: Martin Rama Are Labor Market Policies to Blame?

WPS1874 Health Policy in Poor Countries: Weak Links in the Chain

WPS1875 How Deposit Insurance Affects Financial Depth (A Cross-Country Analysis)

WPS1876 Industrial Pollution in Economic Development (Kuznets Revisited)

WPS1877 What Improves Environmental Performance? Evidence from Mexican Industry

WPS1878 Searching for Sustainable Microfinance: A Review of Five Indonesian Initiatives

WPS1879 Relative prices and Inflation in Poland, 1989-97: The Special Role of Administered Price Increases

WPS1880 Foreign Aid and Rent-Seeking

WPS1881 The Asian Miracle and Modern Growth Theory

WPS1882 Interretional Resource Transfer and Economic Growth in Indonesia
Deon Filmer
Jeffrey Hammer
Lant Pritchett

Robert Cull

Hemamala Hettige

Muthukumara Mani

David Wheeler

Susmita Dasgupta Hemamala Hettige David Wheeler

R. Marisol Ravicz

Przemyslaw Wozniak

Jakob Svensson

Richard R. Nelson

Howard Pack

Toshihiko Kawagoe
January 1998

January 1998

January 1998

January 1998

January 1998

Contact for paper

C. Bernardo 31148

P. Lanjoun 34529

1. Tabada 36896

L. Tabada 36896

s. Fallon 38009

January 1998

S. Fallon 38009

January 1998

P. Sintim-Aboagye 37644

January 1998

D. Wheeler 33401

January 1998

D. Wheeler 33401

February 1998

M. Ravicz 85582

L. Barbone 32556

February 1998

R. Martin 39065

February 1998

C. Bernardo 31148

February 1998

R. Martin 39065 


\section{Policy Research Working Paper Series}

\begin{tabular}{|c|c|c|c|c|}
\hline & Title & Author & Date & $\begin{array}{l}\text { Contact } \\
\text { for paper }\end{array}$ \\
\hline WPS1883 & $\begin{array}{l}\text { Intersectoral Resource Allocation and } \\
\text { Its Impact on Economic Development } \\
\text { in the Philippines }\end{array}$ & $\begin{array}{l}\text { Fumihide Takeuchi } \\
\text { Takehiko Hagino }\end{array}$ & February 1998 & $\begin{array}{l}\text { K. Labrie } \\
31001\end{array}$ \\
\hline WPS1884 & $\begin{array}{l}\text { Fiscal Aspects of Evolving } \\
\text { Federations: Issues for Policy and } \\
\text { Research }\end{array}$ & David E. Wildasin & February 1998 & $\begin{array}{l}\text { C. Bernardo } \\
31148\end{array}$ \\
\hline WPS1885 & $\begin{array}{l}\text { Aid, Taxation, and Development: } \\
\text { Analytical Perspectives on Aid } \\
\text { Effectiveness in Sub-Saharan Africa }\end{array}$ & $\begin{array}{l}\text { Christopher S. Adam } \\
\text { Stephen A. O'Connell }\end{array}$ & February 1998 & $\begin{array}{l}\text { K. Labrie } \\
31001\end{array}$ \\
\hline WPS 1886 & $\begin{array}{l}\text { Country Funds and Asymmetric } \\
\text { Information }\end{array}$ & $\begin{array}{l}\text { Jeffrey A. Frankel } \\
\text { Sergio L. Schmukler }\end{array}$ & February 1998 & $\begin{array}{l}\text { R. Martin } \\
39065\end{array}$ \\
\hline WPS 1887 & $\begin{array}{l}\text { The Structure of Derivatives } \\
\text { Exchanges: Lessons from Developed } \\
\text { and Emerging Markets }\end{array}$ & $\begin{array}{l}\text { George Tsetsekos } \\
\text { Panos Varangis }\end{array}$ & February 1998 & $\begin{array}{l}\text { P. Kokila } \\
33716\end{array}$ \\
\hline WPS1888 & $\begin{array}{l}\text { What Do Doctors Want? Developing } \\
\text { Incentives for Doctors to Serve in } \\
\text { Indonesia's Rural and Remote Areas }\end{array}$ & $\begin{array}{l}\text { Kenneth M. Chomitz } \\
\text { Gunawan Setiadi } \\
\text { Azrul Azwar } \\
\text { Nusye Ismail } \\
\text { Widiyarti }\end{array}$ & March 1998 & $\begin{array}{l}\text { T. Charvet } \\
87431\end{array}$ \\
\hline WPS1889 & $\begin{array}{l}\text { Development Strategy Reconsidered: } \\
\text { Mexico, 1960-94 }\end{array}$ & $\begin{array}{l}\text { Toru Yanagihara } \\
\text { Yoshiaki Hisamatsu }\end{array}$ & March 1998 & $\begin{array}{l}\text { K. Labrie } \\
31001\end{array}$ \\
\hline
\end{tabular}

